\title{
Patent Analysis in the 5G Network
}

\author{
Hui Eva Zhang, Xi'an Jiaotong-Liverpool University, Suzhou, China \\ Kok Hoe Wong, Xi'an Jiaotong-Liverpool University, Suzhou, China \\ Victor Chang, Teesside University, Middlesbrough, UK
}

iD https://orcid.org/0000-0002-8012-5852

\begin{abstract}
In recent years, $5 \mathrm{G}$ has been the focus of research and development in the telecom industry. The year 2019 has become the first year of 5G commercial deployment, and significant countries in the world have started the commercial deployment of $5 \mathrm{G}$ networks. This paper aims to understand the development trend and technical hot spots of 5G technology through the patent analysis and build a citation network at the assignee organization level. The workflow of the paper is divided into four steps: patent data collection and cleaning, patent overview analysis, network creation and analysis, O-I index analysis. This article collected the patent data from the United States patent and trademark office (USPTO). The authors understand the application trend, technical hot spots, and leading players in the $5 \mathrm{G}$ domain through the patent overview analysis. They comprehend the structure and characteristics of the network and critical nodes from network topology analysis. By using O-I index analysis, they learn the flow of $5 \mathrm{G}$ technology knowledge between the organizations. This paper provides a useful analytical model for the patent analysis and technological knowledge flow in a specific field, which can be applied to patent analysis in other fields.
\end{abstract}

\section{KEYWORDS}

5G Network, Patent Network Analysis

\section{INTRODUCTION}

\subsection{The Background of $5 \mathrm{G}$}

$5 \mathrm{G}$ is short for the fifth-generation wireless system or the fifth-generation mobile network $(\mathrm{Hu}, 2016)$, which applies to the next-generation mobile communication standard. In recent years, $5 \mathrm{G}$ has been the research and development (R\&D) focus of the telecommunication industry. In 2012, some nations and areas around the world began to study the needs and technologies of $5 \mathrm{G}$ mobile communication technology (Du et al., 2018). Major global businesses and regions are guiding $5 \mathrm{G}$ development by introducing strategic planning, deploying major projects, releasing spectrum planning and other means. The standardization and commercial application of $5 \mathrm{G}$ is also accelerating significantly (Han et al., 2018). The general agreement is that 5G systems can be launched around 2020 (Zhang et al., 2017). 5G will be different from previous generations of communication networks. The goals of $5 \mathrm{G}$ include creating viable solutions for vertical industries such as the auto industry, healthcare, transportation and utilities. However, it is undeniable that after several generations of development, wireless technology has produced almost inestimable tremendous socio-economic value. $5 \mathrm{G}$ will be 
the first generation with the explicit goal of providing social and economic benefits, so many new $5 \mathrm{G}$ functions are expected to be implemented.

Before discussing the structure and features of the fifth-generation $(5 \mathrm{G})$, it would seem appropriate to clarify the need to design such a network. So it is helpful to look back at the previous generation. From Figure 1, we can know the development of $1 \mathrm{G}$ to $5 \mathrm{G}$ network, such as the general deployment date, theoretical download rate and delay time. For example, 4G, deployed in the 2010 s, provides a theoretical download rate at the speed of $1 \mathrm{Gbit} / \mathrm{s}$ and 60-98 ms delay (ITU, 2018). While 5G, deployed in the 2020s, affords theoretical download rate at the speed of 10Gbit/s and less than $1 \mathrm{~ms}$ delay. $5 \mathrm{G}$ could theoretically offer ten times the speed of 4G, as well as millions of connections and ultra-low latency, which are fundamental to the Internet of things (IoT) (Zhang, 2019). 5G networks aim to meet various customers' service quality requirements in different applications (Zhang et al., 2017). For example, in a place where unseamed wide-area coverage is required, the $5 \mathrm{G}$ network system can equip customers with high-data-rate services at all times, no matter where they are. It is broadly agreed that 5G networks should solve six problems that $4 \mathrm{G}$ networks have not adequately solved, such as higher capacity, higher data rates, lower end-to-end latency, large-scale device connectivity, lower costs and consistent quality of experience (Gupta and Jha, 2015).

Figure 1. The development of wireless network

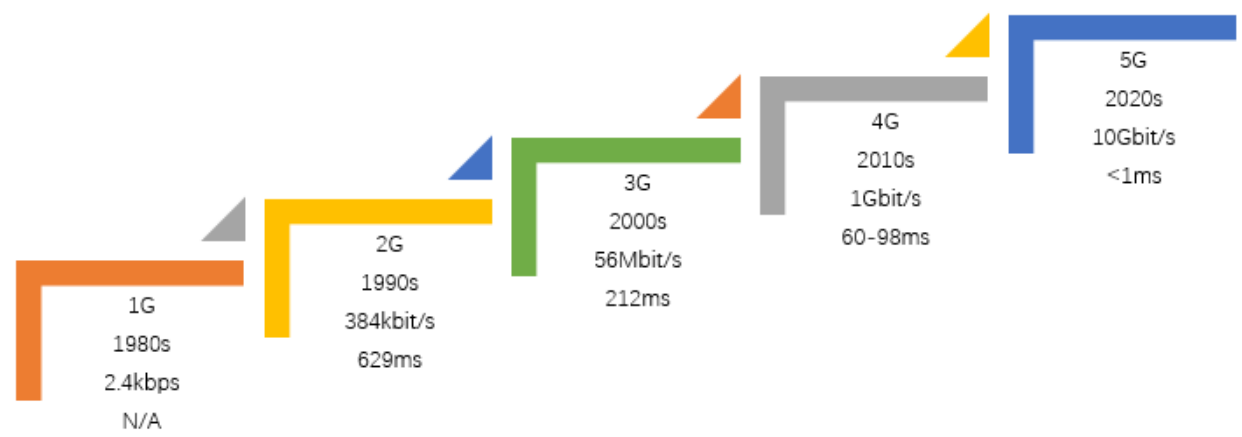

From Figure 2, the three main applications of 5G are continuous widespread coverage and high capacity scenario (eMBB), low delay and high-reliability scenario (uRLLC) and low power consumption and large connection scenario (mMTC) (Liu et al., 2018). In the 5G era, mobile communication will be improved to support IoT business fully cantered on things, people, and objects (Du et al., 2018). The pre-4G technology has created a very brilliant internet economy, While 5G technology opens another door to the industrial Internet era (Zhang, 2019).

The main business of the $5 \mathrm{G}$ network at the initial stage is HD and UHD video, AR/VR and cloud games, which belong to the category of eMBB scenes. The development phase will generate uRLLC scenarios, such as industrial manufacturing, autonomous driving, telemedicine and intelligent transportation. When it reaches the mature stage, it will face massive large-scale application and connection requirements of the Internet of things (Liu et al., 2018). Social progress and demand, in turn, promoted the revolution and progress of the telecommunication system ( $\mathrm{Li}$ et al., 2014). 


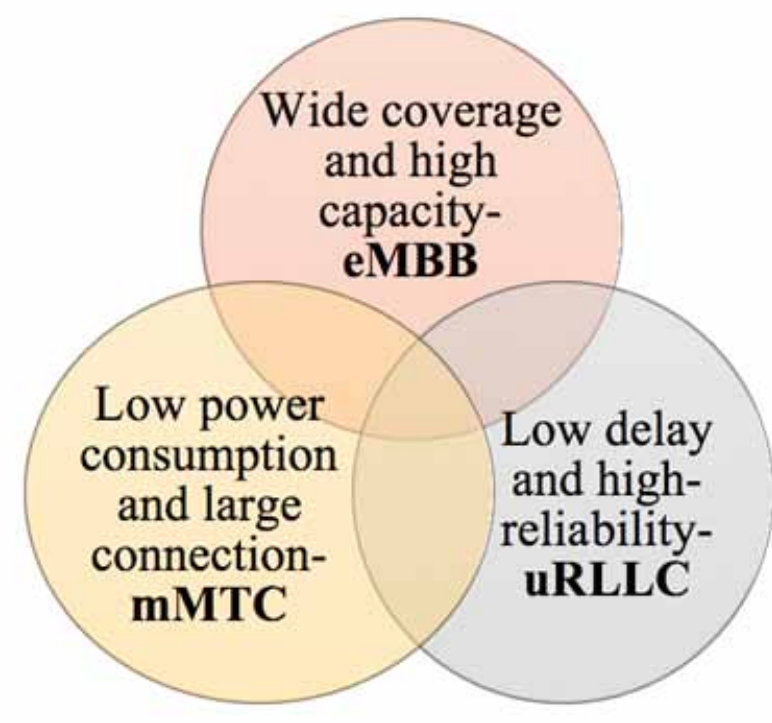

\subsection{Project Aim and Research Questions}

Unlike the $4 \mathrm{G}$ standard and the development of previous generations of wireless networks, participants in the $5 \mathrm{G}$ standardization process were forced to consider new markets and industry categories from the start (ITU, 2018). The development of 5G is a complex process, with the number of participants growing exponentially compared with previous generations of wireless networks, leading to more companies in more industries getting involved. As a result, the $5 \mathrm{G}$ market has evolved into an extremely competitive arena. Given the contribution that companies have made to $5 \mathrm{G}$ over the past five to 10 years, fundamental change in the technology is now impossible, and new entrants cannot change the essential elements of 5G (Hu, 2019). Even so, the market landscape will continue to change as 5G begins to roll out globally. At the same time, patents have become increasingly important. Although the highly anticipated 5G standard was officially approved in June 2018, much work remains to be done to stimulate the growth of $5 \mathrm{G}$. The potentially lucrative $5 \mathrm{G}$ licensing market is just beginning to develop. Several key companies, including Ericsson, Qualcomm, and Nokia, have announced their patent use fee plans. For example, A patent fee of $2.275 \%$ will be charged for phones that use Qualcomm standard necessary patents and only support 5G. Ericsson's 5G patent license fee is $\$ 5$ for high-end handsets and \$2.50 for low-end handsets. Nokia has also announced a charge for 5G, which is 3 euros per phone ( $\mathrm{Lu}, 2018$ ). Besides, there will be considerable patent litigation and regulatory review. Thus, patents are essential for $5 \mathrm{G}$ technology and market development. Patents are products of technological innovation and scientific and technical inventions (Chen et al., 2011). In the increasingly fierce international competition, patent information has become one of the most critical intelligence resources (Zhang et al., 2011). Therefore, the author chose to analyze the patents related to the $5 \mathrm{G}$ network to explore the following research questions:

1) What are the development trend and technical focus of 5G network technology in the last decade?

2) Who are the primary applicants for $5 \mathrm{G}$ network patents? What about their patent citation network?

3) How do technological knowledge flow between assignee organizations? 
The propagation of technology is considered as the movement of technical knowledge between organizations. The flow of technical information from one entity to another is seen as the flow of technical information or knowledge. On account of the understanding, the main research objectives of the study contain the three aspects below:

- To understand the development trend and technical focus of 5G network technology as well as the leading players.

- To establishing a citation network by the collected patent at the assignee organizational level, and discover the characteristics of the network and critical nodes.

- To explore the knowledge flow between the assignee organizations.

\subsection{Methodology and Business Applications}

This paper used and queried the USPTO database in the United States provided by Patsnap company as the data source. Patsnap's global patent database can quickly find accurate information from more than 130 million of patents in 116 countries. The USPTO is a federal agency that grants patents and registered trademarks to the United States, and it has a complete patent citation information for us. This paper will make use of statistical analysis and network analysis to address the research problem. From statistical analysis, we can know the general trends, technical research focus and critical players in the $5 \mathrm{G}$ network. From network analysis, this paper builds patent citation network at the organizational level, focusing on the two points. Firstly, this paper puts forward the structural characteristics of the citation network through topology analysis and visualization and then investigates the significance and value of individual organizations via node centrality analysis. It is meaningful because it provides the overall view of the $5 \mathrm{G}$ domain technical knowledge network and particular knowledge about separate organizations. Secondly, this paper sorts various organizations in the network through O-I index analysis and analyses their functions from the perspective of technical knowledge flow. Then we will be able to understand the flows of technology between assignee organizations in the citation network.

Patent network analysis is by no means just an analysis of its reference relationship. The introduction of assignee organizations into the network can not only enrich the application of network analysis in the patent analysis but also provide enterprises with critical information about technological development. That is conducive to the planning and implementation of technological innovation strategy (Yang and Zhang, 2008). Finally, in the commercial application, the author also hopes to provide the following reference help:

For investors, they can understand the trends, core technology and main participants of 5G network and make better investment decisions;

For innovators and researchers, they will grasp the research hotspots and gaps of 5G network technology and discover the technical strength of patent applicants;

For policymakers, they will learn about the development of $5 \mathrm{G}$ from the national level to improve the national competitiveness and support for $5 \mathrm{G}$ infrastructure.

\section{LITERATURE REVIEW}

\subsection{Patent Analysis}

Patents refer to proprietary rights and interests. A patent is generally a document containing the content of an invention or creation issued by a government agency or organization based on an application, and an invention-creation that has been patented in a certain period can only be implemented with the permission of the patentee (Griliches, 1990). Patents generally fall into three categories: invention, utility model and design (Zhang et al., 2014). The rights of patent last typically for up to 20 years for invention and ten years for utility and appearance design from the date the application was filed (WIPO, 2018). According to patent law, patents are regional and exclusive. Applying for a patent 
in a country can cover a specific technical field of the country and form a patent enclosure, market enclosure, or even monopoly. It has become one of the primary means for multinational enterprises to seize and control foreign markets by legally occupying a particular technical field through the patent application (Lv and Kang, 2010). As we can see from Figure 3, the trend of global intellectual property application set a new record in 2017, with the global patent application volume reaching 3.1 million and about a 6\% increase compared with 2016 (WIPO, 2018). Patent analysis is a unique and practical method in enterprise strategy and competition analysis. The importance of patent analysis lies in planning the direction of technology development, breaking through technical barriers, expanding independent space, reducing R\&D funds, and enhancing international competitive advantage. With the rapid growth of technology nowadays, both high-tech and traditional industries attach increasing importance to patent analysis (Yang and Zhang, 2008).

Figure 3. Patent application worldwide(2001-2017)

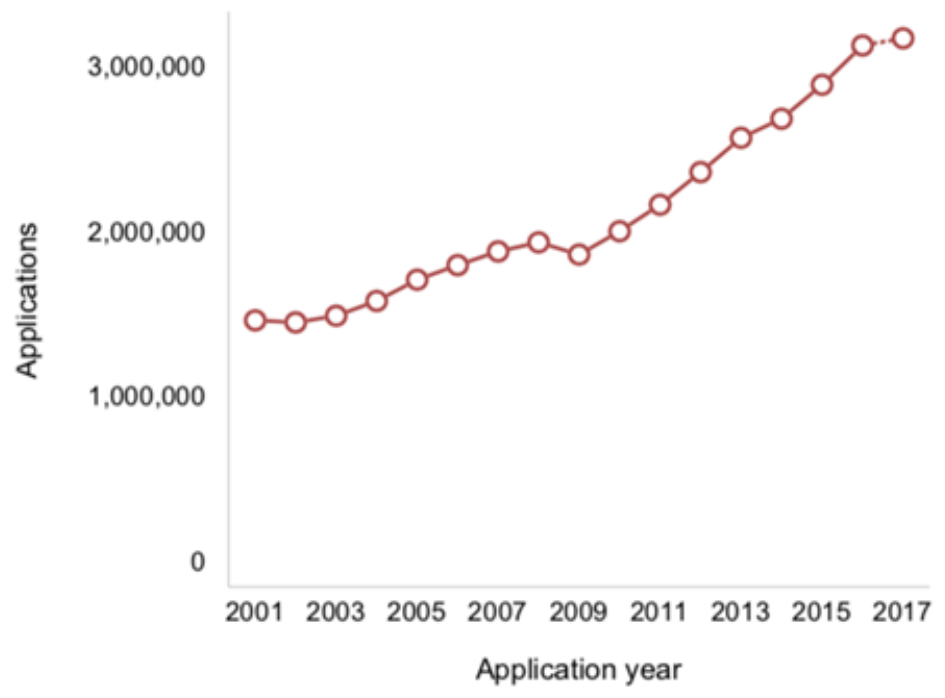

Currently, patent analysis mainly focuses on four areas (Figure 4): Patent statistical analysis, co-occurrence analysis, clustering analysis and citation analysis. Here is more information about the four areas. Patent statistical analysis analyses information such as patent application date, owner information, inventor, country, IPC. This information can help us to grasp the development trend and overview of the patents collected.

Patent co-occurrence analysis refers to the phenomenon of the feature item information appearing together through the analysis of patent classification number, applicant, inventor, country of the patent application, etc. Patent clustering analysis uses text mining technology to reveal the distribution of a specific technology field and patents of significant competitors. The citation and cited information of the target patent are analyzed to disclose the correlation of technology and the development of technology route when it comes to Patent citation analysis. From 1963 to 2006, scientists from the national bureau of economic research (NBER) made great efforts to provide citation information of American patents, and patent citation research has significantly been developed (Sharma and Tripathi, 2017). 


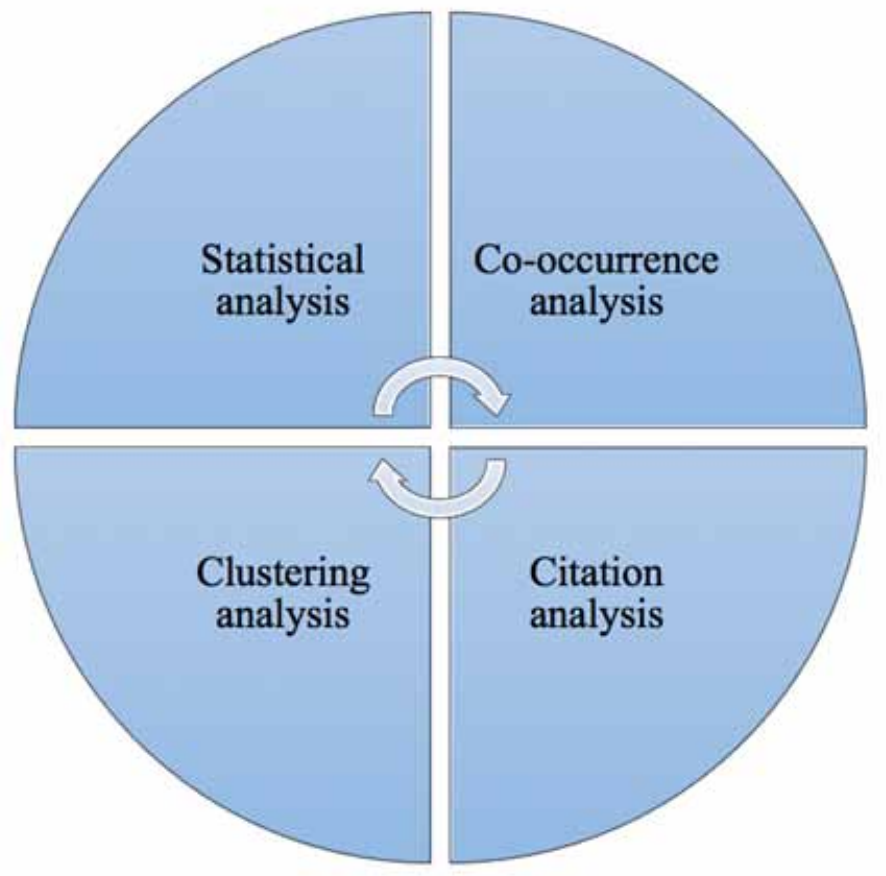

The digitization of patent data boosts the value and availability of patent research (Sharma and Tripathi, 2017). Later national innovators, researchers, and company managers agreed that patent databases were an essential source of technical information (Madani and Weber, 2016). They recognized that technology is an important and crucial determinant, both for national competitiveness and endogenous growth in the macro and micro impacts (Sharma and Tripathi, 2017). In general, current technologies are based on existing technologies. The more times a patent is cited, the more significant the impact of the technology. Also, we can find core patents according to the size of the patent family. In this way, we can screen the core technologies of industries or competitors, understand competitors' protection strategies for core patents, determine the development trend and latest application of technologies, study patent citation and its owner relationship, and discover the technical strength of patent applicants.

\subsection{Using Social Network Analysis (SNA) for Patent Analysis}

In 2008, German scholars pointed out that social network analysis, as an advanced patent analysis technology, had just entered the field of patent analysis and had a broad application prospect (Sternitzke et al., 2008). In recent years, social network analysis (SNA) has attracted more and more attention as a research method (Zhang et al., 2011). The theoretical basis of SNA originated in the 1930s and matured in the 1960s and 1970s. Among them, the essential ideas mainly include GRANOVETTER's weak connection theory, BURT's structure, hollowness theory, and LIN's social capital theory represented by Xiang and Cai (2012). SNA methods provide visualization analysis tool and abstract data of patent literature in network graphic representation, and better support decision-making (Zhang et al., 2011). The primary function of this method in the application of patent analysis rests with the citation network, cooperation network, co-occurrence network or associated network, and so on. The specific performance in patent citation analysis or cited analysis, the inventor or the patentee 
cooperation, technical topics (IPC) co-occurrence analysis, thus to identify the core patents, found significant prediction technology development trends and the inventor or competitors (Liu, 2014).

The application research of patent intelligence analysis based on SNA mainly focuses on five aspects (Zhang and Xiao, 2013): A. Research on network characteristics and network influencing factors. For example, Hung and Wang's (2010) research on the small-world phenomenon of patent citation network and its power-law distribution characteristics, Wilhelmesson's (2009) spatial distribution status and causes of inventor cooperation network. B. Competitive and cooperative intelligence research. That is, to grasp the competitive situation through SNA analysis. For example, Zhang et al. (2011) used SNA to analyze core patents, technical field distribution and development trends, competitor analysis and competitive region analysis of semiconductor chips. Wang et al. (2010) examined the technological level and core competitiveness of the world's top 500 enterprises by citing the patent matrix. C. Application research in core technology testing, technology theme association, technology cluster, technology evolution. For example, Luan and Zeng (2011) used the network centrality index to conduct technical network analysis on the global aerospace industry patents in 2009. Kuusi and Meyer (2007) made use of the patented coupled network to survey the scientific prediction in the nanotechnology field. D. Application research in knowledge flow, knowledge management. HAN and Park (2010) build a knowledge flow network between traditional and emerging industries in South Korea based on patent data, the industry as node and knowledge flow based on patent citation as the network edge. They conductesearch on the connection between scientific and technological innovation, scientific research and technological innovation. Breschi and Catalini (2010) analyzed the vital role of high-degree intermediary points in scientific and technological innovation through the cooperation network of scientists and inventors.

\subsection{Limitations and Ascendancy of Patent Citation Analysis}

Citation information included in patents or technological publications is generally considered to be the most necessary and vital measure of influence (Chen and Hicks, 2004). In particular, patent reference is widely considered to stand for knowledge overflow or knowledge transfer (Slope, 2002) and has been widely employed to measure the intangible knowledge flow between technical fields (Karki, 1997). There are, however, some weaknesses to using patent data as an index of the flow of technical knowledge. The first shortcoming is whether patents can be used to stand for technical knowledge for not all inventions or innovations are patented or patentable (Archibugi and Pianta, 1996). The second disadvantage is that different technical departments have different tendencies towards patents (Basberg, 1987). Some companies may prefer to protect their business secrets or trademarks on their own. Third, not every patent has equal value or impact for the quality varies from each other. There are very few patents with real high technology and commercial value. So the three deficiencies may reduce the significance and worth of patent data (Choe et al., 2013). Despite these shortcomings, since the importance of patents is usually proportional to the number of citations, many endeavors have been made to study the flow of knowledge using patent data (Lee and Kim, 2010). Additionally, patent reference can give knowledge about the distribution of technology in a specific technosphere and clearly show the development trajectory of technology (Chang et al., 2009). Also, patent references provide a link between the predecessor and the descendant of the technology (No and Park, 2010). Therefore, patent reference has developed into one of the leading measures to illustrate the technological relationship.

$\mathrm{Hu}$ and Jaffe (2003) employed patent citation data to study the knowledge expansion system between countries. No et al. (2010) tried to use patent references in the field of nanobiology to deepen the understanding of technology track and trend. Kajikawa and Takeda (2009) examined OLED information citation networks to discover rising research areas. Choe et al. (2013) studied the organic photovoltaic cells industry to grasp the construction and features of technological knowledge flow from three aspects: country, organization and technology field. Patent data represent a direct result of the invention process, which is their impressive benefit (Han and Park, 2006). Even if not all 
inventions can be patented, patents serve as some of the most vital measures of technical innovation and intelligence.

\subsection{Focus of this Research}

Previous research papers on 5G mainly focus on technology, commercial applications and standard formulation. Very few research were conducted on the analysis of 5G networks' patents. Sharma (2013) introduced the development of the mobile wireless communication network from $1 \mathrm{G}$ to $5 \mathrm{G}$. Gupta and Jha(2015) conducted a detailed study on the performance requirements of the 5G wireless cellular communication system. Li et al. (2015) put forward the principal elements and technologies of $5 \mathrm{G}$ network capacity and discussed how to realize such capacity growth in ten years, to have a greater opportunity to increase the capacity of the system. Liu and $\mathrm{Li}(2016)$ extracted keywords based on the white paper and scientific and technological literature and conducted statistical analysis on the annual application trend of 5G patents, applicants, IPC and patentee competitiveness. Xiao and Zhao(2017) analyzed the patent layout and technology competition situation of domestic and foreign enterprises in the field of $5 \mathrm{G}$ communication based on patent measurements, such as statistics, social network analysis and visualization tools. Zhang et al. (2017) introduced a logic architecture of a 5G system based on network slices. Dighriri et al. (2018) proposed a new 5G network resource allocation scheme, which can dynamically allocate network resources to different pieces to ensure user satisfaction and demand. Liu et al. (2018) studied and verified the critical issues of a commercial-oriented 5G network. Han et al. (2018) introduced the progress of the major 5G international standardization organization and domestic standardization. Du et al. (2018) summarised 5G mobile communication technology standards and looked forward to the development trend of $5 \mathrm{G}$ standards.

Traditional methods use statistical analysis of the patent number and citation frequency to understand the flow of technical knowledge (Jaffe and Trajtenberg, 1999). However, due to the limitations of these methods, only part of the information about the diffusion of technical knowledge can be provided ( $\mathrm{Li}$ et al., 2007). Network analysis is the analysis of the relationship between nodes or their structures, generally using network topology analysis and node centrality analysis. Network topology analysis analyses the entire network make-up and the relationship between nodes, while node centrality analysis helps determine the value of each node in the network (Choe et al., 2013). Therefore, this paper conducted a more comprehensive study combining statistical analysis and network analysis.

First of all, from the perspective of data volume, this paper selected the top 30 relevant patent application organizations with more than 100 patents in the USPTO database, instead of only analyzing the top 5 or top 10. The author obtained 13,443 patents and the reference information of these patents, including 561522 backward and 20796 forward citations. For patent overview analysis: innovation rate, technology focus, cell diagram and wheel of innovation were carried out. For network analysis, this paper implemented visualization, network analysis, k-cores decomposition, and node centrality analysis. Indegree centrality, outdegree centrality and betweenness centrality were chosen to classify nodes in O-I index analysis. Although a large amount of data will increase the difficulty of data processing, it can make the analysis more comprehensive. Moreover, the combination of statistical analysis and cluster analysis with network analysis can make better use of the patent data to obtain some insights.

\section{METHODOLOGY}

\subsection{Research Framework}

Figure 5 shows the study analysis schema of the paper. This study began from gathering patents related to the $5 \mathrm{G}$ network in the USPTO database from platform Patsnap. The reason for choosing the USPTO database is that the USA is the world's largest patent market and the database is well-organized and 
has sound citation information (Lee et al., 2018). The author then collected the patents that met the requirements by building the patent query keywords and setting the screening criteria. After that, we could get the patents in the $5 \mathrm{G}$ domain and download them and their citation information (backward citation and forward citation) from platform Patsnap, including the citing and cited information of each patent.

Because the downloaded patent data need to be further cleaned up for data analysis, and the amount of data is relatively large, the author spent much time in data cleaning. For example, downloaded information of citing and cited patents was improved, so that the data could be used for the later network construction. Besides, some patent applicant's names were in Chinese, Japanese, or Korean. They were needed to be unified if they are the same applicant. For example, “Apple INC." and “苹 果公司”, “Intel corporation” and “英特尔”. Sometimes, some organizations' names may have more or less a symbol (like space, comma, letter, or period), and they were also needed to be merged as one. For instance, "HUAWEI TECHNOLOGIES CO., LTD.", "HUAWEI TECHNOLOGIES CO., LTD," and "HUAWEI TECHNOLOGIES CO. LTD.", both of which look almost the same. However, they are different because of one more dot or one less comma. When doing statistical analysis and network analysis, the author will find that Huawei has several names, which will confuse the results. Next, the author constructed the assignee organization network with the cleaned backward and forward citation information. Finally, the paper carried out the research analysis in the third stage: patent overview analysis, network analysis and O-I index analysis. There will be more introductions and details in section 5 about stage three.

\section{Figure 5. Research workflow chart}

Stage 1

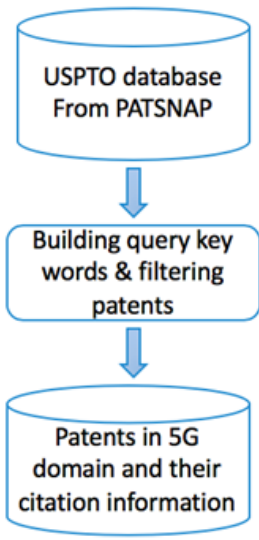

Stage 2
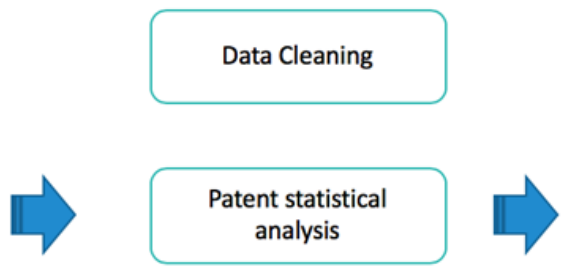

Assignee organization citation network

\section{Stage 3}

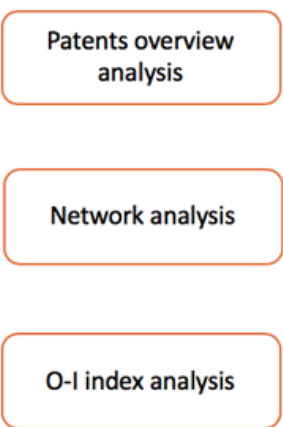

\subsection{Measures for Patent Analysis}

For data cleaning, patent overview analysis and O-I index analysis, the paper uses the software Power query and Tableau. In order to analyze the network, the paper uses network statistics such as average degree, graph density, number of components, average clustering coefficient, network diameter, average path length. They have been widely utilized in the social network analysis to comprehend the network in SNA (Albert and Barabási, 2002). Then the authors visualized the assignee 
Table 1. Statistics and node centrality for network analysis

\begin{tabular}{|c|c|}
\hline Statistics & Definition \\
\hline Number of Nodes & The total number of nodes in a network. \\
\hline Number of Edges & The total number of links in a network. \\
\hline Average degree & $\begin{array}{l}\text { Degrees are the number of links between one node and } \\
\text { other nodes. The average degree is the sum of the } \\
\text { degrees of all nodes divided by the total number of nodes } \\
\text { in the network. }\end{array}$ \\
\hline Graph density & $\begin{array}{l}\text { The density of a graph is the ratio of the number of edges } \\
\text { and the number of possible edges }\end{array}$ \\
\hline $\begin{array}{l}\text { Number of } \\
\text { components }\end{array}$ & $\begin{array}{l}\text { The component is an independent sub-network in a } \\
\text { network. The number of components means the number } \\
\text { of isolated groups in a network. }\end{array}$ \\
\hline Clustering coefficient & $\begin{array}{l}\text { The clustering coefficient of a node is the ratio of the } \\
\text { actual number of links to the maximum possible number } \\
\text { of links between these neighbors. The clustering } \\
\text { coefficient of the network is the mean clustering } \\
\text { coefficient of all nodes. }\end{array}$ \\
\hline Average path length & $\begin{array}{l}\text { The average path length can be taken between any pair of } \\
\text { nodes in the network. It is a measure of the efficiency of } \\
\text { information or mass transmission over a network. }\end{array}$ \\
\hline Network diameter & $\begin{array}{l}\text { Network diameter is to measure the maximum shortest } \\
\text { pathway between any two nodes in the network. }\end{array}$ \\
\hline Degree centrality & $\begin{array}{l}\text { Degree Centrality is the most direct measure to } \\
\text { characterize the centrality of nodes in network analysis. It } \\
\text { calculates the number of connections one node has with } \\
\text { other nodes in a network. The higher degree of a node, } \\
\text { the higher degree of centrality of the node, and the more } \\
\text { critical the node are in the network. } \\
\text { The normalized DC computational formula is: } \\
\qquad C_{R D I}=\mathrm{d}(\mathrm{I}) /(\mathrm{n}-1)\end{array}$ \\
\hline
\end{tabular}




\begin{tabular}{|c|c|}
\hline $\begin{array}{l}\text { Betweenness } \\
\text { centrality }\end{array}$ & $\begin{array}{l}\text { Betweenness centrality }(\mathrm{BC}) \text { counts the number of } \\
\text { shortest paths that pass a point, which is the sum of the } \\
\text { fraction of all-pairs shortest paths that go through the } \\
\text { point. It is measured by using the sum of the shortest } \\
\text { path length between one node and all the other nodes. } \\
\text { The normalized } B C \text { computational formula is: } \\
C_{\text {RBS }}=2 C_{\text {ABI }} /[(n-1)(n-2)]\end{array}$ \\
\hline Closeness centrality & $\begin{array}{l}\text { Closeness centrality }(\mathrm{CC}) \text { measures the total distance } \\
\text { from one point to all other points. The smaller the sum, } \\
\text { the shorter the path from one point to all the other } \\
\text { points, the closer this point is to all the other points. It } \\
\text { represents how close a node is to other nodes. The } \\
\text { normalized CC computational formula is: } \\
C_{R P \text { I }}^{-1}=C_{A P i}^{-1} /(n-1)\end{array}$ \\
\hline Eigenvector centrality & $\begin{array}{l}\text { Eigenvector centrality is used to measure the transfer } \\
\text { influence and connectivity between nodes. It is the } \\
\text { measurement method to consider the transfer influence } \\
\text { of nodes, rather than the direct importance of nodes. In } \\
\text { the eigenvector centrality, connecting nodes with high } \\
\text { scores significantly contribute to connecting nodes with } \\
\text { low scores. } \\
\tilde{A}_{i j}=A_{i j} / \sum_{i j} A_{i j} \text {. }\end{array}$ \\
\hline
\end{tabular}

organizations' network by Gephi and implemented centrality analysis to study the key and valuable nodes. Visualization technology serves as a critical role in the application of SNA. At present, the most commonly used visualization social network analysis software in China mainly includes Pajek, CiteSpace II, Python, R, Gephi and so on. In this paper, Gephi is adopted in the paper because it can well calculate and visualize large and complex networks. Table1 shows the definitions of the measures used in the study for the later network analysis.

\section{DATA ACQUISITION AND NETWORK BUILDING}

In this research, the authors collected the patent data from the United States Patent and Trademark Office (USPTO) by a patent search and analysis company called Patsnap. Founded in 2007, Patsnap has a paid global patent database for searching patents around the world and can quickly find accurate information from more than 130 million of patents in 116 countries. In the United States, the federal 
agency that grants US patents and registered trademarks in the USPTO, which owns complete patent data and their citation information. According to Sharma and Tripathi (2017), the USPTO patent database was used in $98 \%$ of published research papers on patent citations and related topics, which means that patent citation data offered by the USPTO can be used as a trustworthy source for a research project. Therefore, the paid Patsnap patent database has been used as a source and platform for $5 \mathrm{G}$ patent analysis.

Firstly, the authors made a query to the registered patents in $5 \mathrm{G}$ networks on the patent title, abstract and claims in the USPTO database. The query words searched here is constructed by Boolean logical connector "or" \& "and":

"IPC:(H04B OR H04W OR H04L or G06F) and (TAC:( '5G network' or 'fifth generation network' or 'fifth generation communication' or ' $5 \mathrm{G}$ communication' or ' $5 \mathrm{G}$ wireless' or 'fifth generation wireless' or 'eMBB' or 'uRLLC' or 'mMTC') or DESC:( 'eMBB' or 'uRLLC' or 'mMTC' or '5G network')".

IPC is short for the International Patent Classification. Since the authors did not want irrelevant patents, the technical scope of the patent is limited to H04B (Transmission), H04W (Wireless communication networks), H04L (Transmission digital information) and G06F (Electric digital data processing). TAC means the keywords needed to be searched in the abstract. The paper chose the "5G network" or its synonyms or the three main application scenario of $5 \mathrm{G}$ ( ' $e M B B$ ' or ' $u R L L C$ ' or ' $m M T C$ ') as the keywords. DESC is short for description in the claims, and the paper chose the " $5 \mathrm{G}$ network' and the three main application scenarios of $5 \mathrm{G}$ ('eMBB' or ' $u R L L C$ ' or ' $m M T C$ ') as the keywords to get more accurate about patents the $5 \mathrm{G}$ network.

In order to extract valid and non-duplicate patents, the author filters the patents by patent type, data grouping, legal status, application year and assignees:

Patent type: invention; Data grouping: one document per application; Legal status: excluding withdrawal, non-payment and expired; Application year: 2009-2018; Assignee: Top 30 assignees with the number of patents in $5 \mathrm{G}$ networks larger than 100 .

Next, the goal is to screen the representative patents and leading players in the field of 5G mobile networks and identify their relations to each other. In the first search, we found 13443 legally valid invention patents in 5G network and acquired data on 561522 backward and 20796 forward citations of these patents. Backward citation means a patent cites contents from other previous patents, and forward citation means other later patents cite a patent. The paper focuses on the assignees who apply the patents and their citation network, so the author created the assignee organization citation network by using the links of the patents. Here is the workflow of the network building in Figure 6.

\section{Figure 6. The workflow of the assignee organization citation network}
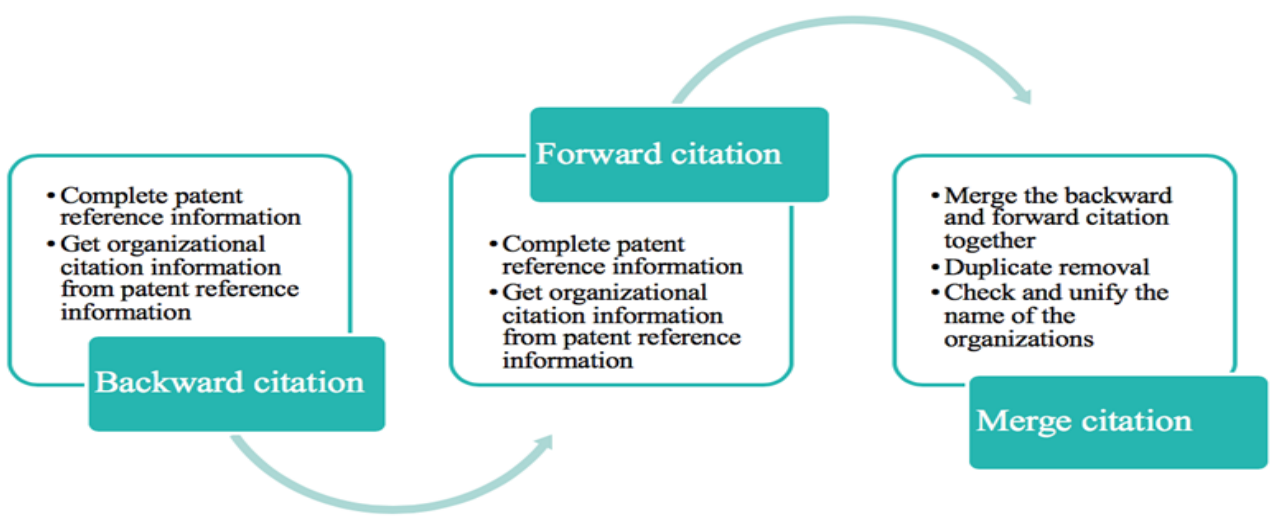
The explanation is as follows. First, we should improve and complete the downloaded data on the backward and forward patent citation to prepare for the construction of the network. The tables of data from the Patsnap database need to be transformed and populated with PowerBI to facilitate subsequent analysis. While some of the information is not very structured and organized, we also need to clean the data before integration. Then we can extract the assignee organization citation information from the patent reference information. There are citation links between the assignees of the patents if a patent cites others or has been citede by other patents. Some of the patents may have more than one assignee. In order to focus on the important nodes in the network, we chose the first assignee listed in the top 30 assignees with the number of patents larger than 100 . Top 20\% and $30 \%$ of patents will have its meaningful focus and research interest (Geuna and Nesta, 2006). Next, we need to merge the backward and forward citation as the form of source and target in one file and remove the duplicate links. It is worth noting that sometimes the same applicant will have different names or representations, so it is necessary to check and unify the organization's name to build a better citation network. Finally, the paper obtained the assignee's directed citation network with 4449 nodes and 7799 edges $^{1}$.

\section{RESULTS OF OUR ANALYSIS}

\subsection{Patent Analysis Overview}

\subsubsection{Innovation Rate}

Figure 7 shows the annual trend from the year 2009 to 2018 in the 5G network technology field. Trends in published patent applications are shown in green color, and trends in published granted patents are shown in yellow color. The graph indicates the counts of applied patents each year in the 5G network began to increase quickly after the year 2013 and reached a peak in 2017, and the number of granted patents each year also reached the top at the year of 2017 and began to decrease since then. The percentage of granted patents has been reduced since 2013 and achieved less than $20 \%$ in 2018. From the graph, we can conclude that the 5G network technology has entered the maturity

Figure 7. Innovation rate from the year 2009-2018 in 5G network

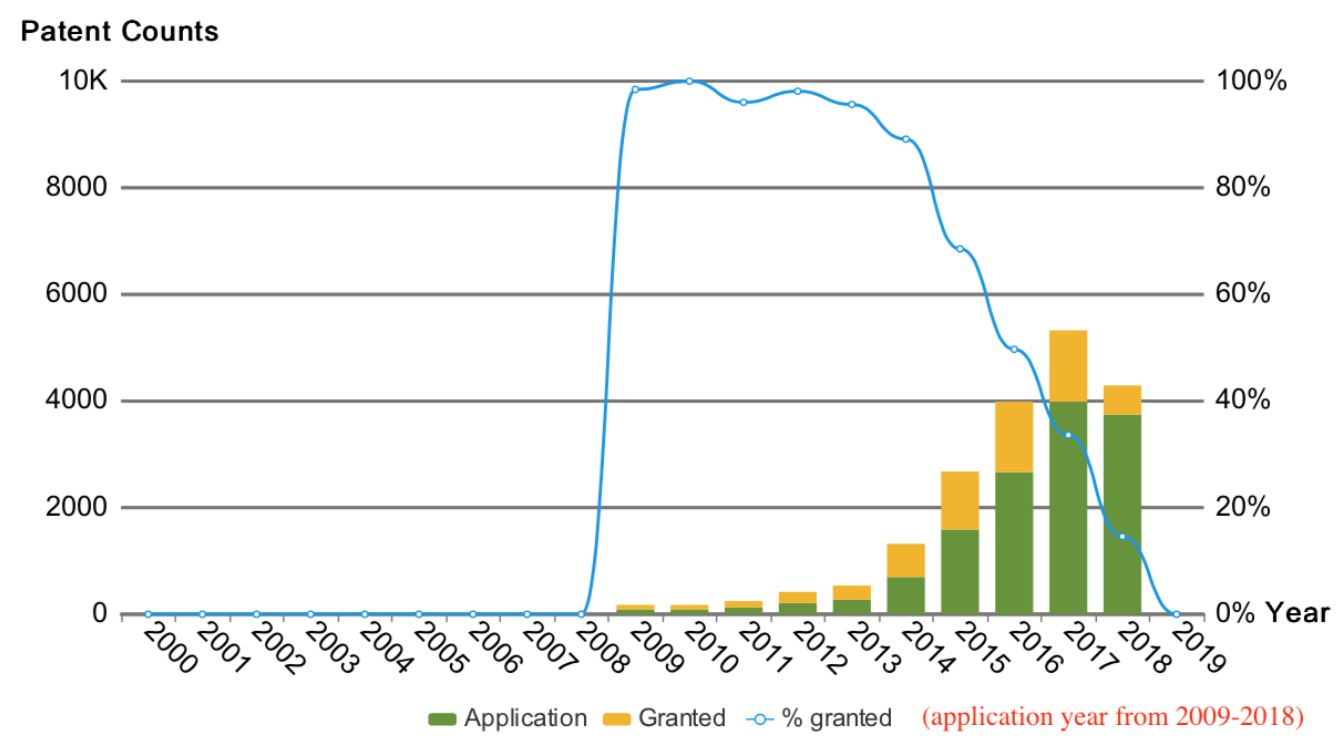


period since 2018, and the maturity of technology will drive the development of business. China, the United States, South Korea and the United Arab Emirates will all launch 5G commercial services in 2019. Canada, Mexico, Australia, Japan and more than 10 Asia-pacific countries/regions and more than 20 European countries will also launch 5G commercial services in 2020.

1 The number of assignee's links is fewer than 582318 patents links (backward citations+forward citations) for the weight (number of citations) is not revealed in the citation network construction.

Canada, Mexico, Australia, Japan and more than 10 Asia-pacific countries/regions and more than 20 European countries will also launch 5G commercial services in 2020.

\subsubsection{Technology Focus}

Figure 8 visualizes the top 10 technology categories in the field of technology employed in all collected patents, with the box area proportional to the number of patents. It helps to understand the possible and potential applications of different technologies. This information can be used to identify opportunities for cross-industrial application of the specific technology field. This paper uses IPC (the International Patent Classification) to classify the technology. IPC provides a classification system of irrelevant linguistic symbols for the classification of patents and utility models according to the different technical fields involved in patents and utility models (WIPO, 2019). IPC divides the technology domain into eight parts, with a total of about 70,000 branches. Each part consists of a symbol made up of Arabic numerals and Latin letters. IPC is continuously revised, and new editions are published regularly.

Figure 8. Top 10 technology focus of the patents in the $5 \mathrm{G}$ network

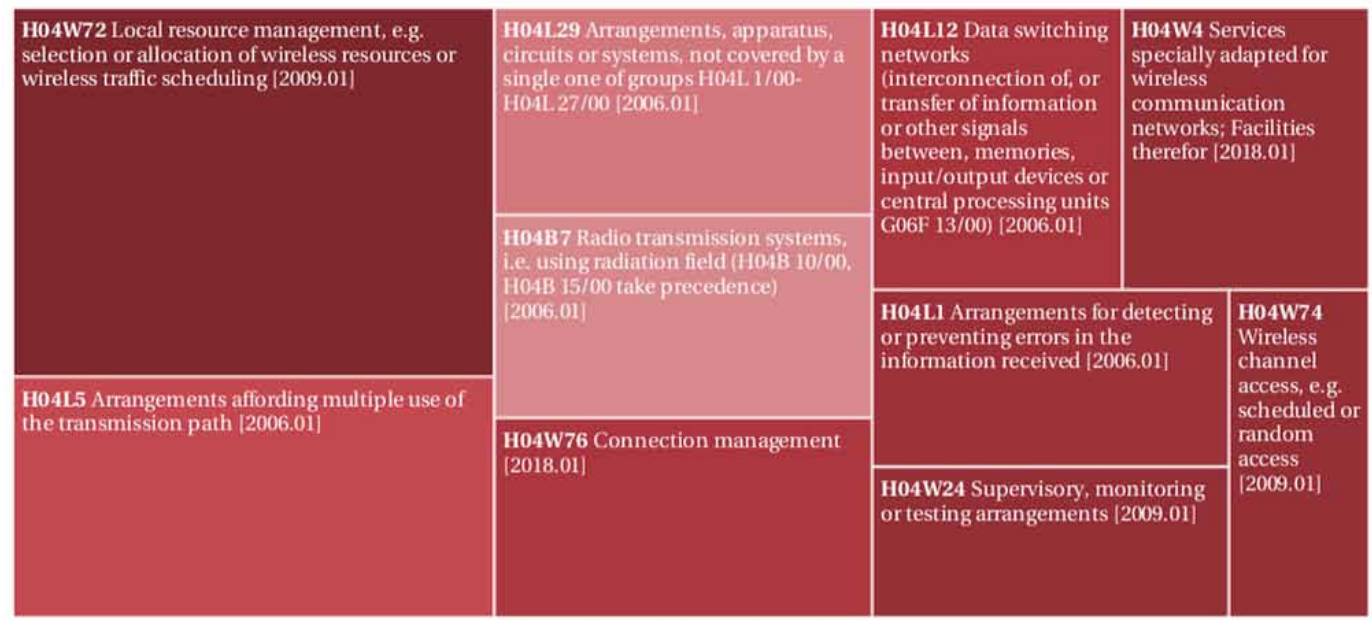

We can see from Figure 8 that the top 5 IPC groups are H04W72, H04L5, H04L29, H04B7and H04W76. We can also see more information about the IPC from the description in Figure 8. H04W72 represents the local resource management; H04L5 is arrangements affording multiple uses of the transmission path; H04L29 means arrangements, apparatus, circuits, or systems, not covered by single one of groups; H04B7 is radio transmission systems and H04W76 is connection management. The top 5 IPC groups cover up more than $50 \%$ of the technology focus in the $5 \mathrm{G}$ patents we collected. 


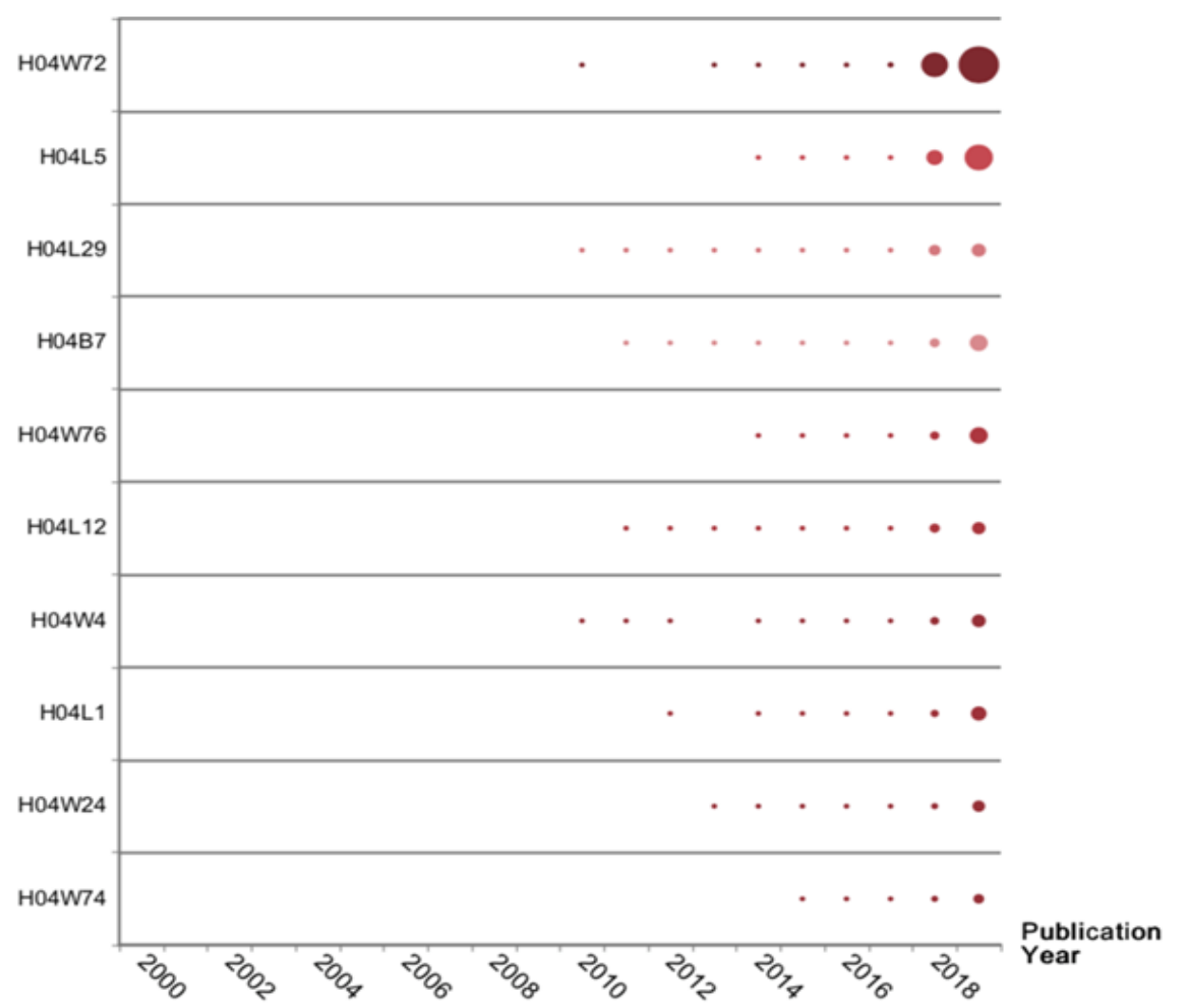

To know how the technological direction of the searched technology changed over time, the authors use Figure 9 to show the yearly patenting trend of published patents by technology area. The size of the circle represents the number of patents filed in that particular year. From Figure 9, we can observe that in the year 2017, the technological direction began to change considerably, with H04W72 and H04L5 in the leading role in 2017 and 2018. The number of patents filed by IPC H04B7 and H04W76 was also relatively high in 2018, following H04W72 and H04L5.

\subsubsection{Cell Diagram and Wheel of Innovation}

The cell diagram shows the keywords and phrases of the patents belonging to the top organizations in the technology field. The dependent coverage is represented by the number of cells in each organization, with each cell serving the same amount of patents. Figure 10 provides context and more in-depth insight into the concepts correlated to the top 5 organizations in the $5 \mathrm{G}$ network technology field. For example, the 5G technological focus of Qualcomm is in wireless communication, user equipment, base station and a reference signal. In contrast, Intel focuses more on user equipment, wireless communication and computing device. After all, the top 5 concepts are Wireless Communication, User Equipment, Base Station, Network Node and Reference Signal in the cell diagram, which means the top 5 organizations focus much attention on these technologies.

The wheel of innovation (Figure 11) is used to explain more information about these concepts to know more about the five concepts. The Circle Chart categorizes the most repeated keywords into 


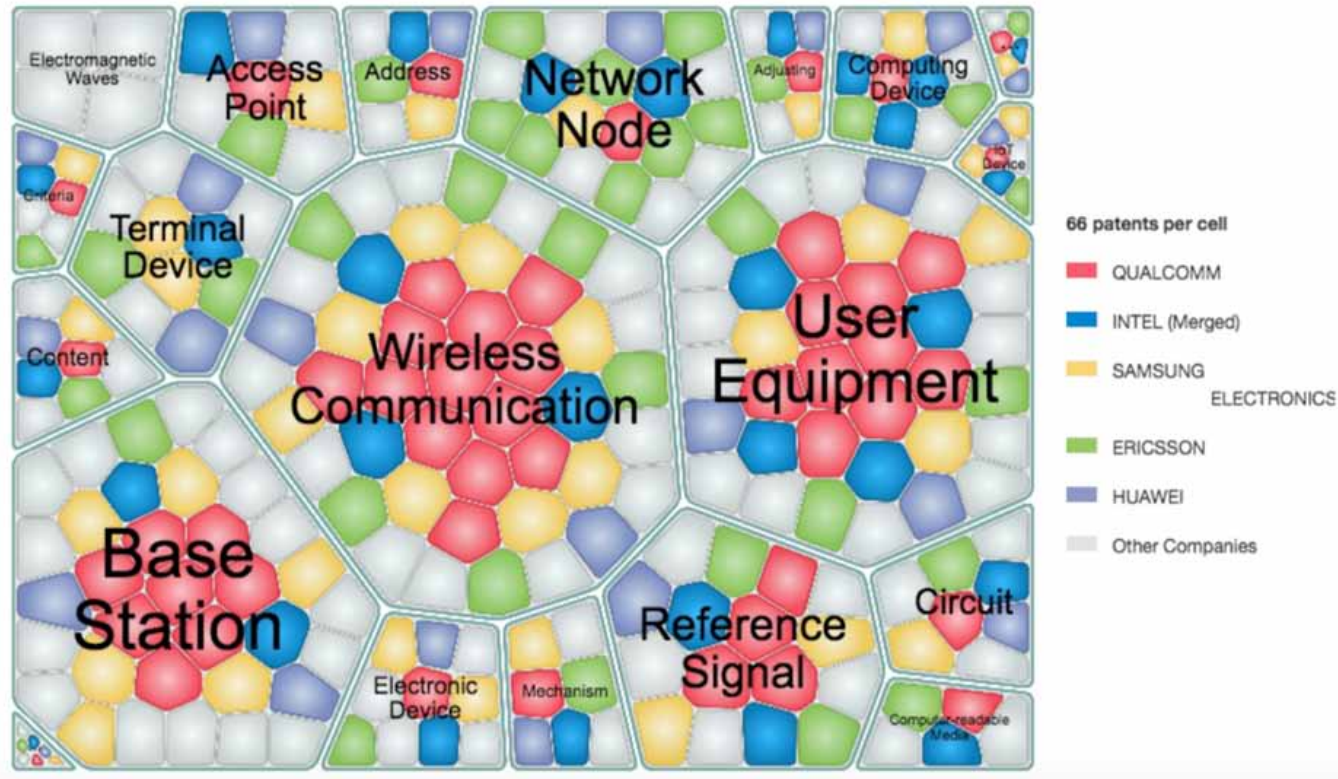

a 2-tier level of the Patents in the technology field. It can help us to arrange the keyword focus and various technologies of patents in a more fine-grained and structured way in the technology domain.

"Wireless communication" consists of keywords such as $5 \mathrm{G}$ communication, control information, control channel, downlink control, radio access. "User equipment" includes a wireless communication system, control information, data transmission, control channel, radio access. "Base station" contains a wireless communication system, control information, 5G communication, control channel. "Network node" mainly covers the wireless device, communication on systems, plurality. "Reference signal" comprises wireless communication, wireless device, control information, channel control. It is easy to see that these five sets of concepts have overlapping fields. The keywords like control information, control channel, wireless communication system, radio access control information appear many times in them.

\subsubsection{G Major Players}

Figure 12 shows the portfolio sizes of the top organizations in the $5 \mathrm{G}$ technology field, which can help us understand the most significant players and the threat of competition in the technology field. The USA makes up 5 of the top 10 organizations, while Europe and Korean accounts for two separate, and the remaining one from China. Please note that the data represents the patents applied in the USA.

Qualcomm ranks first with 2069 patents, followed by Intel and Samsung with 1675 and 1550 patents separately, while Ericsson and Huawei rank fourth and fifth. Information about these companies can be easily searched according to the Internet, such as Baidu, Google and company web pages. In order to better understand the company represented by these nodes in the network, a brief introduction is necessary. Founded in 1985, Qualcomm is the world's primary developer of 3G, 4G and 5G technologies. It has licensed its technology to many global brands or manufacturers, including all of the world's telecommunications and consumer electronics equipment. Intel, founded in 1968 in the USA, is a company concentrating on the evolution of CPU processors, and it is the world's largest manufacturer of components and CPUs for personal computers. As the largest subsidiary of Samsung Group, Samsung Electronics is also the largest electronics company in South Korea. Founded Sweden 
Figure 11. Wheel Of Innovation

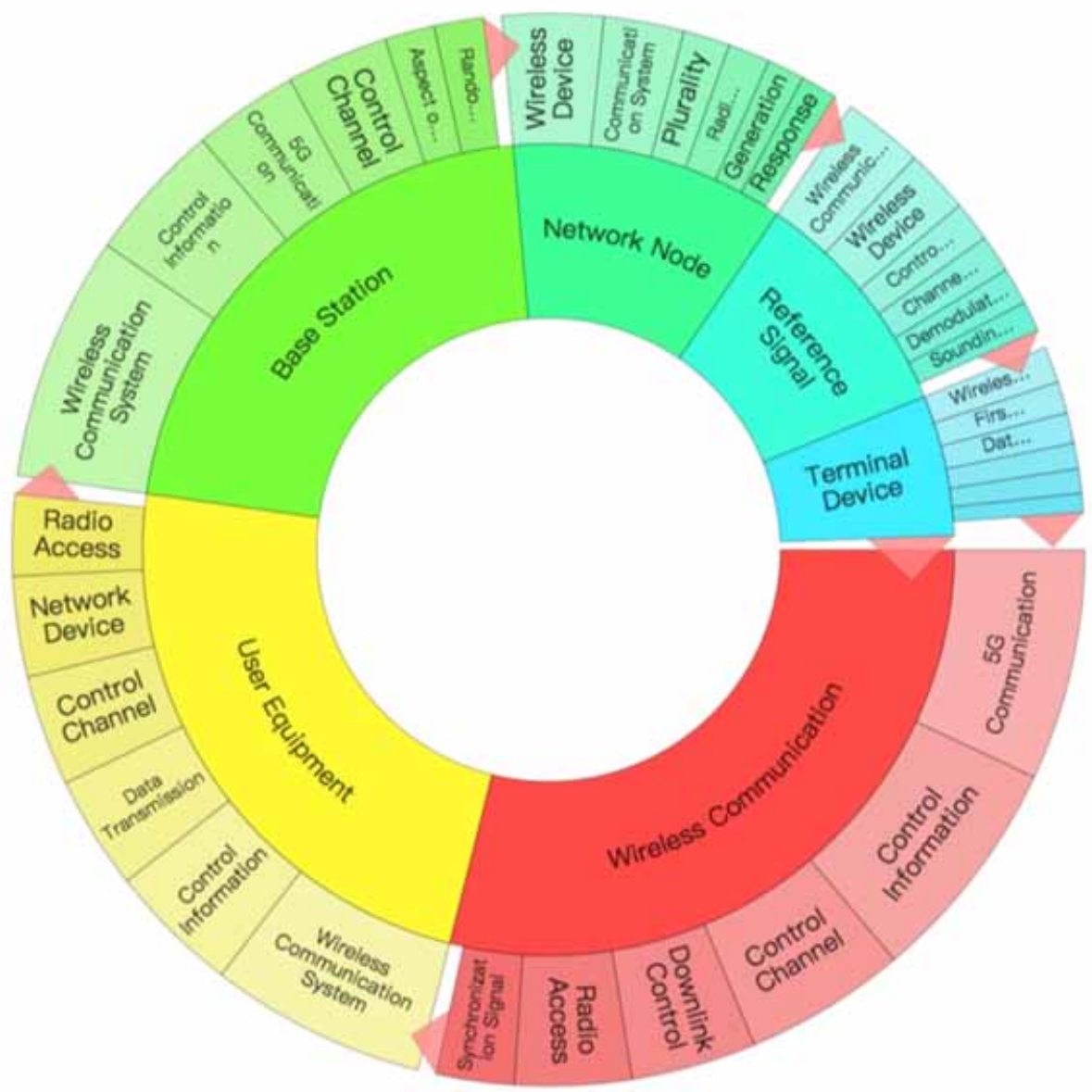

Figure 12. Leading companies in the $5 \mathrm{G}$ network (Counts)

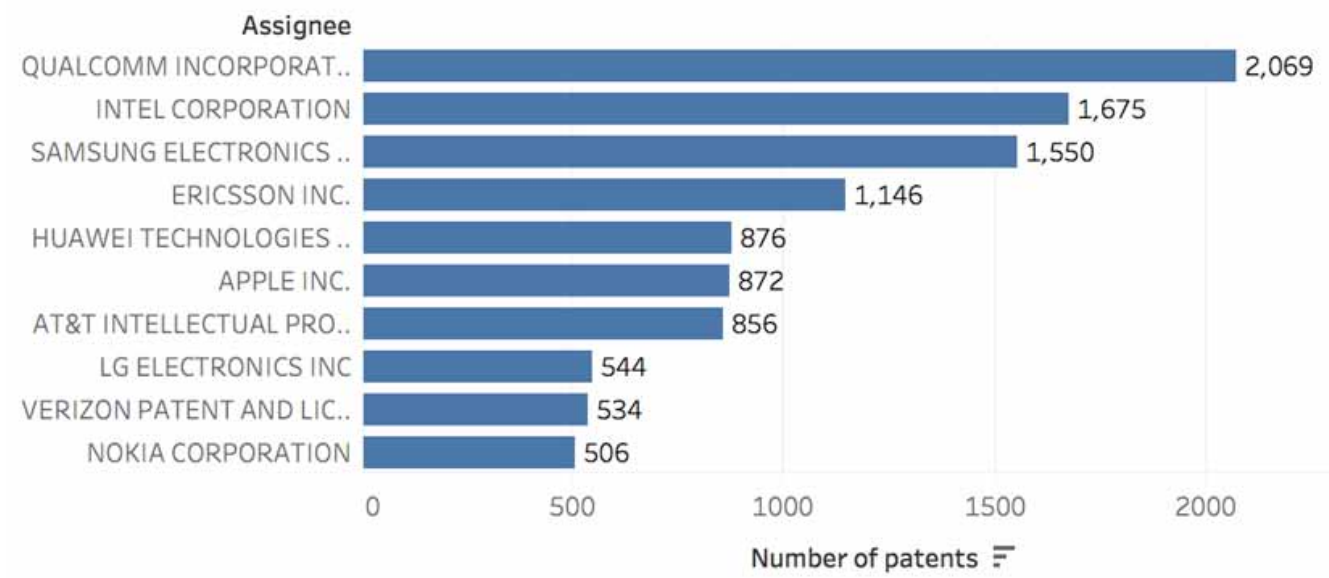


in 1876, Ericsson is also the global leader in wireless communications standardization. Ericsson's wireless networks are widely used and deployed by major operators around the world. Huawei technologies co., LTD., founded in 1987, is a famous and private company in China, mainly engaged in the research and development and manufacturing of communication equipment. After 30 years of development, Huawei has about 190,000 employees, and its business has expanded to more than 170 countries around the world. Huawei has become a primary worldwide provider of information and communication technology (ICT) solutions.

In order to understand the proportion of patents in all patents of the top 10 organizations, the authors used percentages in Figure 13 instead of numerical expressions in Figure 12. From Figure 13, Qualcomm accounted for $19.47 \%$, Intel $15.76 \%$, Samsung electronics $14.58 \%$, Ericsson $10.78 \%$, Huawei $8.24 \%$, etc. From this chart, we can see that the proportion of patents for each company is not too different, and no company can monopolize $5 \mathrm{G}$ technology. The proportions of patents are all between $14 \% \sim 20 \%$, especially for the first three companies.

Figure 13. Leading companies in the $5 \mathrm{G}$ network (percentage)

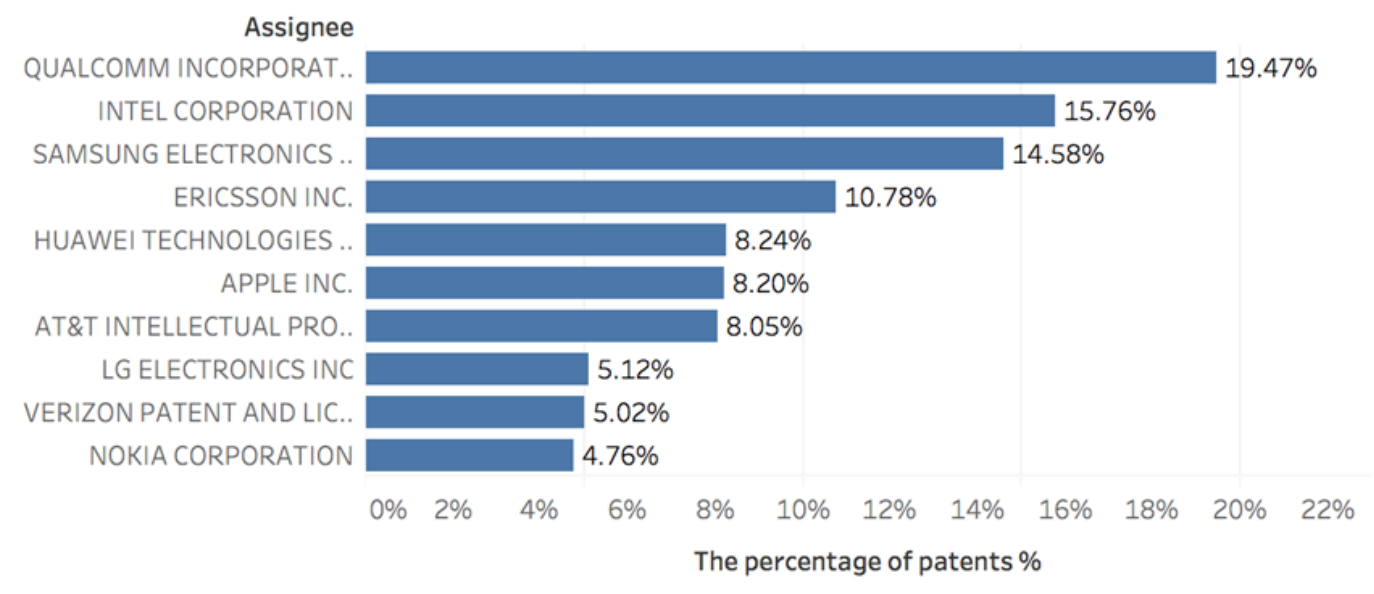

\subsection{Network Analysis}

This paper used the Gephi for visualizing and analyzing the citation network. Here are the results of the network. Table 3 reveals the statistics results of the entire assignee citation network. The network is composed of 4449 nodes and 7799 links with a low graph density of 0.000 . The graph density is approaching 0 , indicating that the number of citation links between patent applicants in the whole network is relatively low. The average degree is 1.753 , which means that assignees in the network have a relationship with 1.753 organizations on average. The average path length value is 2.734 , meaning the average steps along the shortest paths for all possible pairs of network nodes is 2.734 . Network diameter is 4, that is, the maximum shortest paths between any two nodes in the network is 4. We can find that in such a network, most of the nodes are not inter-connected (graph density is 0 ), but most of the nodes can be reached within a few steps, which suggests a small-world phenomenon in the network (Duncan J Watts and Steven H. Strogatz, 1998).

Table 4 indicates the percentage of components in the assignee citation network. Figure 14 visualizes the entire citation network in the 5G technology field. The size of the nodes is arranged by the degree and the color of the nodes by modularity. From table 4 and Figure 14, we can see that 
Table 3. Results of the entire assignee citation network

\begin{tabular}{|l|l|}
\hline \multicolumn{1}{|c|}{ Statistics } & \multicolumn{1}{c|}{ value } \\
\hline Number of Nodes & $\mathbf{4 4 4 9}$ \\
\hline Number of Edges & 7799 \\
\hline Average degree & 1.753 \\
\hline Graph density & 0.000 \\
\hline Modularity/Number of components & $0.500 / 6$ \\
\hline Average clustering coefficient & 0.192 \\
\hline Average path length & 2.734 \\
\hline Network diameter & 4 \\
\hline
\end{tabular}

Table 4. The components in the assignee citation network

\begin{tabular}{|l|l|}
\hline \multicolumn{1}{|c|}{ Component } & \multicolumn{1}{c|}{ Percentage } \\
\hline $\mathbf{1}$ & $30.52 \%$ \\
\hline $\mathbf{2}$ & $28.52 \%$ \\
\hline $\mathbf{3}$ & $26.14 \%$ \\
\hline $\mathbf{4}$ & $6.54 \%$ \\
\hline $\mathbf{5}$ & $4.16 \%$ \\
\hline $\mathbf{6}$ & $4.12 \%$ \\
\hline
\end{tabular}

the entire network is divided into six components, with the leading node APPLE INC. and AT\&T INTELLECTUAL PROPERTY covers $28.52 \%$ and $26.14 \%$ separately of all nodes, which are the second and third largest groups of the network. The largest group covers $30.52 \%$ of all nodes, composed of leading nodes such as HUAWEI, SAMSUNG, INTEL, VERIZON PATENT, SPLUNK and MICROSOFT. Despite the three most significant groups in the network, QUALCOMM, GOOGLE and IBM form the other three different small groups that cover $14.82 \%$ in total.

From Figure 14, we can see the structure of the entire network at a glance, but because there are too many nodes and links in the diagram, it looks complicated and we can hardly see the point. Therefore, the author uses k-core decomposition to visualize the network more clearly. The k-core decomposition can recognize specific subsets of the network, called k-cores, and every k-core is achieved by recursively deleting all the vertices less than $\mathrm{k}$ until all the remaining vertices have a degree higher than or equal to $\mathrm{k}$ (Alvarez-Hamelin et al., 2006).

Figure 15 shows 22 nodes and 433 edges included in the subset of 31-core. Also note that most of the nodes in the citation network have self-referential arrows, indicating that it is common for organizations to refer to their own previous patents due to inheritance and improvement of previous research. APPLE INC. and AT\&T INTELLECTUAL PROPERTY are located in the center of the cluster. SAMSUNG, QUALCOMM, INTEL, VERIZON PATENT are the bridges to connect other components. Google, HUAWEI, IBM and Microsoft act as a role in connecting the periphery nodes.

This phenomenon can also be seen in table 5, which shows the top 10 assignee organizations ranked by four centralities. In Table 5, more than half of the companies are from the USA, and most of them are the leading organizations in the electronics and telecommunications industry. Except 
for Google, which is an internet technology company. Apple INC. and AT\&T INTELLECTUAL PROPERTY I, LP occupy the most critical positions among them, followed by QUALCOMM INCORPORATED, SAMSUNG ELECTRONICS and INTEL, which can be observed from the ranks and frequency of occurrence in Table 5.

Figure 14. Assignee Citation network in 5G technology

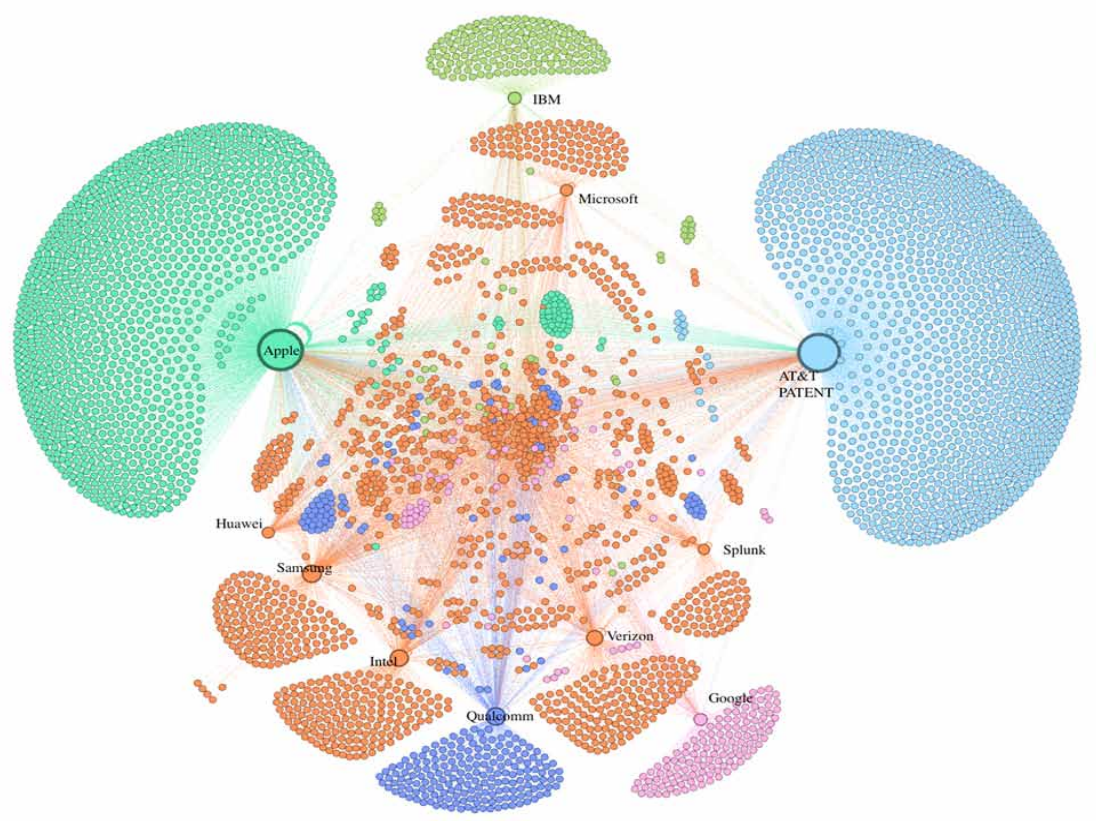

Figure 15. Assignee Citation 31-core network

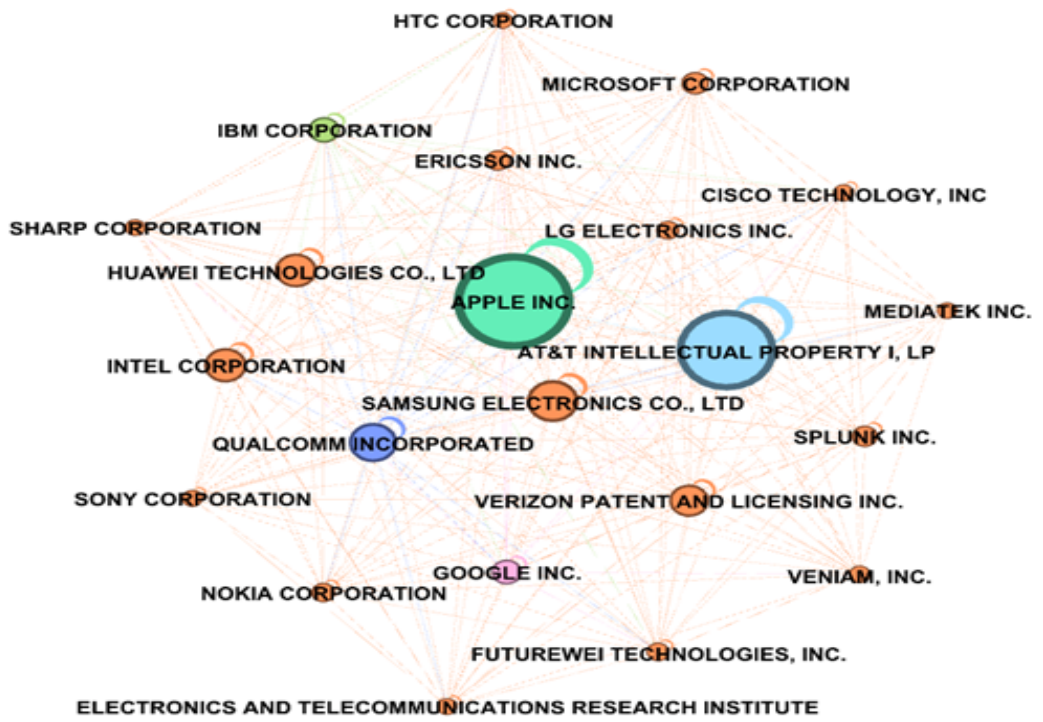


Table 5. Top 10 assignee organizations with the highest centrality in the $5 \mathrm{G}$ network

\begin{tabular}{|l|l|l|l|}
\hline \multicolumn{1}{|c|}{ Degree Centrality } & \multicolumn{1}{c|}{ Value } & \multicolumn{1}{c|}{ Closeness centrality } & \multicolumn{1}{c|}{ Value } \\
\hline APPLE INC. & 0.118 & APPLE INC. & 0.658 \\
\hline $\begin{array}{l}\text { AT\&T INTELLECTUAL PROPERTY } \\
\text { I, LP }\end{array}$ & 0.109 & SAMSUNG ELECTRONICS CO., LTD & 0.604 \\
\hline QUALCOMM INCORPORATED & 0.038 & QUALCOMM INCORPORATED & 0.571 \\
\hline SAMSUNG ELECTRONICS CO., LTD & 0.037 & INTEL CORPORATION & 0.560 \\
\hline $\begin{array}{l}\text { INTEL CORPORATION } \\
\text { VERIZON PATENT AND LICENSING }\end{array}$ & 0.035 & $\begin{array}{l}\text { VERIZON PATENT AND LICENSING } \\
\text { INC. }\end{array}$ & 0.548 \\
\hline IBM CORPORATION & 0.029 & HUAWEI TECHNOLOGIES CO., LTD & 0.533 \\
\hline GOOGLE INC. & 0.019 & AT\&T INTELLECTUAL PROPERTY I, LP & 0.526 \\
\hline MICROSOFT CORPORATION & 0.019 & ERICSSON INC. & 0.521 \\
\hline HUAWEI TECHNOLOGIES CO., LTD & 0.016 & LG ELECTRONICS INC. & 0.518 \\
\hline BetweennesS centrality & Value & Eigenvector centrality & 0.517 \\
\hline APPLE INC. & 0.068 & AT\&T INTELLECTUAL PROPERTY I, LP & 1.000 \\
\hline $\begin{array}{l}\text { AT\&T INTELLECTUAL PROPERTY } \\
\text { I, LP }\end{array}$ & 0.054 & APPLE INC. & 0.918 \\
\hline SAMSUNG ELECTRONICS CO., LTD & 0.022 & QUALCOMM INCORPORATED & 0.437 \\
\hline QUALCOMM INCORPORATED & 0.020 & INTEL CORPORATION & 0.417 \\
\hline $\begin{array}{l}\text { INTEL CORPORATION } \\
\text { VERIZON PATENT AND LICENSING }\end{array}$ & 0.016 & $\begin{array}{l}\text { VERIZON PATENT AND LICENSING } \\
\text { INC. }\end{array}$ & 0.391 \\
\hline IBM CORPORATION & 0.008 & SAMSUNG ELECTRONICS CO., LTD & 0.378 \\
\hline GOOGLE INC. & 0.008 & MICROSOFT CORPORATION & 0.351 \\
\hline HUAWEI TECHNOLOGIES CO., LTD & 0.006 & GOOGLE INC. & 0.349 \\
\hline MICROSOFT CORPORATION & 0.006 & HUAWEI TECHNOLOGIES CO., LTD & 0.288 \\
\hline
\end{tabular}




\subsection{O-I Index Analysis and Grouping}

We use two metrics to locate individual nodes on the matrix and then classify them into different quadrants. To better weigh the level of technical information inflow (inflow) and innovation quality (outflow) of an individual node in the network, this paper introduced the outflow - inflow (O-I) index, as shown in the following formula:

$$
O-\text { I index }=\frac{(\text { outdegree centrality-Indegree centrality })}{(\text { Outdegree centrality+Indegree centrality })}
$$

The value of the O-I index is in the middle of -1 and 1 (Choe et al., 2016). If the value of the $\mathrm{O}-\mathrm{I}$ index is more than 0 , this implies that the figure for cited patent links is more than the figure for citing patent links. Moreover, if the value is not more than 0 , it says that the number for cited links is less than the number for citing links. A node has higher artistic quality when its O-I index gets closer to 1, and increases the influx of knowledge when its O-I index gets closer to -1 conversely. Therefore, in the $5 \mathrm{G}$ technology citation network, we can easily discover whether a specific node is a technology producer or a technology absorber.

The O-I index contrasts the number of backward links and forward links at the individual node level(Choe et al., 2016), so it can hardly show more knowledge about the location of a unique node in the entire network. That is the reason why we introduce the betweenness centrality (BC) as the other matrix index. From table 1, we can know the definition of the $\mathrm{BC}$ is to compute the figure for the shortest paths that passing a node. If the $\mathrm{BC}$ of a node is high, the node will serve as a critical role in transferring technology flows in the entire network and be seen as agents or brokers regularly. By combining the O-I index and BC together, we can study the role of each node in the 5G technology networks cause the matrix analysis provides a method of node classification on account of knowledge flow.

Figure 16 shows the distribution of assignee organizations in the matrix with the O-I index as the $\mathrm{X}$-axis and betweenness centrality as the $\mathrm{y}$-axis. From Figure 16, we can classify the nodes into four categories (Choe et al., 2016): (A) Agents of technical knowledge generation, (B) Agents of technical knowledge absorption, (C) Technical knowledge producer, (D) Technical knowledge absorbers. The four categories have the characteristics below:(A) $\mathrm{O}-\mathrm{I}$ index $>0$, and the $\mathrm{BC}$ is comparatively high. (B) $\mathrm{O}-\mathrm{I}$ index $<0$ and the $\mathrm{BC}$ is relatively high. (C) $\mathrm{O}-\mathrm{I}$ index $>0$, and the $\mathrm{BC}$ is comparatively low. (D) $\mathrm{O}-\mathrm{I}$ index $<0$ and the $\mathrm{BC}$ is comparatively low.

Group A acts as a role in creating patents that are highly attractive for invention, bridging the flow of technical knowledge in the $5 \mathrm{G}$ field. Group B shall actively absorb technical knowledge in the field of $5 \mathrm{G}$ and play the role of intermediary of technical knowledge. The assignee organizations in group A or B are the leading nodes, most of which are in the center of the network and own many edges or links. Group C or D owns most of the organizations in the network. The organizations in Group $\mathrm{C}$ supply technical intelligence to the $5 \mathrm{G}$ domain, and the value of their outdegree centrality and $\mathrm{BC}$ is low. Group D absorbs technical knowledge but has a low value of in-degree centrality and BC. From the network diagram, groups $\mathrm{C}$ and $\mathrm{D}$ are usually located in the boundary.

In Figure 16, we can see organizations such as Qualcomm, Samsung electronics co., Ltd, Huawei technologies co.,ltd, Futurewei, Nokia, Ericsson and LG electronics are in group A, which means they play a role in brokers on account of knowledge producer. Especially Huawei technologies co.,ltd, Nokia, LG Electronics, Samsung electronics co.,ltd and Ericsson, they are the top 6 patent owner of $5 \mathrm{G}$ declarations as to the number of patent families (IPlytics, 2019) and play essential roles in the 5G essential standards-setting. In group B, there are companies like Apple INC., AT\&T intellectual, Intel, IBM, Verizon patent, Google, Microsoft corporation and Splunk INC. They work as brokers based on knowledge absorption. Group B actively absorbs technical knowledge of the 5G field and 


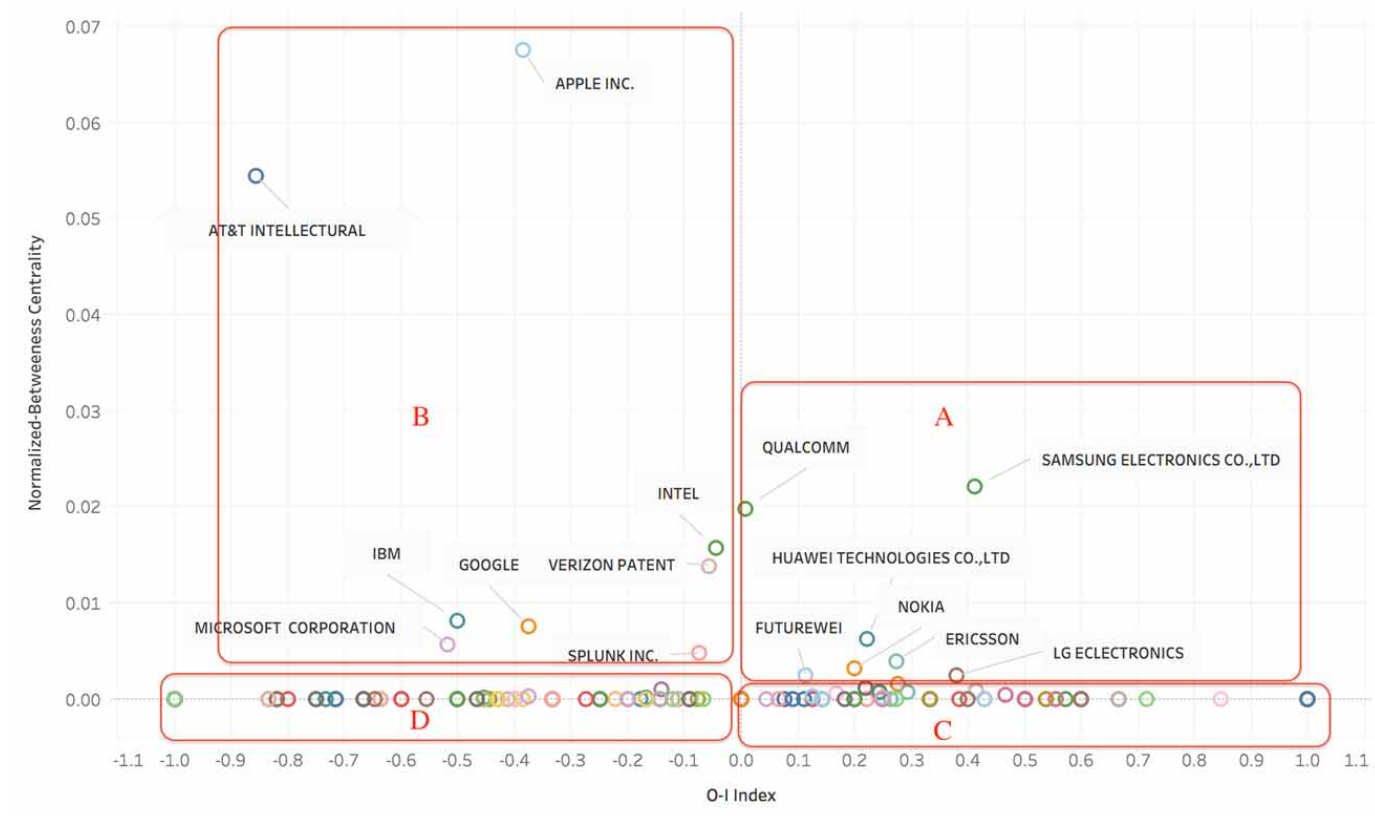

applies it in various fields. They will focus more on the development of technical knowledge to understand the application in life.

The total number of nodes in the assignee organization network is 4449 , so the rest of the unlabeled nodes are in group C and D. Also, We can give some well-known company names in group $\mathrm{C}$ and $\mathrm{D}$ as below:

Alcatel, Hitachi, NTT, Avago, Alibaba, CommScope technologies are in group C, which mainly provides technology innovation to the $5 \mathrm{G}$ field. Groupon INC., KT Corp, Hyundai motor, ADEMCO group and OPPO mobile are in group D, and they primally absorb the technology in 5G domain. In the process of data processing, the author found that some organizations account for a large part of patent self-citation, such as Qualcomm, Apple, Samsung, Huawei and other leading players. Regardless of whether the assignee organizations are knowledge producers, assimilators or intermediaries in terms of patents.

\section{DISCUSSION}

\subsection{Summary of Our Analysis}

In summary, the patent analysis performed suggests the following results:

- The 5G network technology life cycle has entered the maturity period since 2018, and the maturity of technology can drive the development of business applications later on. The technical focus of 5G technology are H04W72, H04L5, H04L29, H04B7and H04W76, and the keywords and phrases of the patents belonging to the top organizations in the technology field are wireless communication, user equipment, base station, network node and reference signal in the cell diagram

- Figure 12 shows the top 10 patent assignee organizations in the $5 \mathrm{G}$ technology field in the USPTO database. From the proportion of patents in all patents of the top 10 organizations in Figure 13, 
we know that no company can monopolize 5G technology right now. From the results of the entire assignee citation network, we can find a small-world phenomenon exists in the 5G patent citation network. APPLE INC and AT\&T INTELLECTUAL PROPERTY occupy the most critical positions in the network from the visualization of citation network and node centrality. SAMSUNG, QUALCOMM, INTEL, VERIZON PATENT are the bridges to connect other components. Google, HUAWEI, IBM and Microsoft act as a role in connecting the periphery nodes. Moreover, it is common for organizations to refer to their own previous patents due to inheritance and improvement of previous research.

- Qualcomm, Samsung Electronics, Huawei, Futurewei, Nokia, Ericsson and LG electronics are in group A in Figure 16, which means they play a role in brokers on account of knowledge producer. Companies like Apple INC., AT\&T intellectual, Intel, IBM, Verizon patent, Google, Microsoft corporation and Splunk INC. are in group B, which are seen as brokers based on knowledge absorption and actively absorbs technical knowledge and applies it in various fields. Furthermore, most of the organizations belong to group $\mathrm{C}$ or $\mathrm{D}$, which are just knowledge producer or absorber.

\subsection{Limitation of Our Research}

Despite the author's endeavor to make a comprehensive analysis, there were some unavoidable limitations. Since the patent data utilized in the paper was collected from the USPTO database, it might not represent a global prototype of $5 \mathrm{G}$ patents. Moreover, since not all patents and scientific publications on $5 \mathrm{G}$ were taken as the object of analysis, it was not possible to conclude that the results of this research stand for the global development of $5 \mathrm{G}$ and the entire flow of technical knowledge in 5G. Besides, the paper did not consider the weight of articles (number of citations) when building the network, so the significance and worth of the crucial nodes may be underestimated in the citation network. One main reason is that we found that some of the organizations' patent self-citations were too many: AT\&T Intellectual Property's self-citation is about 30000 and Apple INC's self-citation is about 20000 while most companies' self-citation is in single digits, which was not well reflected in the network even though the author intended to differentiate the links by weight in Gephi. Finally, the authors do not go into the specific IPC references between organizations for technology flows, because almost all patents have more than one IPC category.

\section{CONCLUSION AND FUTURE WORK}

This paper aimed to grasp the development trend, technology focus and leading players of 5G, as well as the structure and knowledge flow of the $5 \mathrm{G}$ citation network at the assignee organization level. The workflow of the paper was undertaken in four steps: Patent data collection and cleaning, patent overview analysis, network creation and analysis and O-I index analysis. For patent overview analysis, innovation rate, technology focus, cell diagram and 5G major players were carried out. Visualization, topological network analysis, k-cores decomposition, and node centrality analysis were implemented for network analysis. O-I index analysis was used as an extension of network analysis, which could combine in-degree centrality, outdegree centrality and betweenness centrality to classify nodes into four groups.

Through our patent analysis, 5G technology was ready to go. Due to the influence of corporate business and strategy, the research focus of leading owners of 5G patents could vary from each other. As 5G began to roll out globally, the market landscape could continue to change. In summary, this paper provided an overview of patent analysis for $5 \mathrm{G}$, as well as a useful analytical model for the overall analysis and discovery of technical knowledge networks for patents in a particular domain.

In future research, we will recommend refining the keywords of patent search with more accuracy query words, which can be extracted by reading white papers on critical $5 \mathrm{G}$ technologies or consulting relevant professionals. The collected patents should involve 5G key technologies, especially related 
to $5 \mathrm{G}$ declared Standard Essential Patents. In order to make the analysis more comprehensive, the patents can be gathered from different countries' primary global patent databases. At the same time, we should pay attention to removing duplicate patents, such as patents in the same family. Besides, if we can find reliable patents' value data and understand the calculation mode of these data, we can further enhance the enterprise and academic values of the research.

\section{ACKNWOLEDGMENT}

This work is partly supported by VC Resarch (VCR 0000065). 


\section{REFERENCES}

Albert, R., \& Barabási, A. (2002). Statistical mechanics of complex networks. Reviews of Modern Physics, 74(1), 47-97. doi:10.1103/RevModPhys.74.47

Alvarez-Hamelin, J.I., Dall'Asta, L., Barrat, A., \& Vespignani, A. (2006). Large scale networks fingerprinting and visualization using the $k$-core decomposition. Academic Press.

Archibugi, D., \& Pianta, M. (1996). Innovation surveys and patents as technology indicators: the state of the art. Innovation, patents and technological strategies. OECD.

Basberg, B. L. (1987). Patents and the measurement of technological change: A survey of the literature. Research Policy, 16(2), 131-141. doi:10.1016/0048-7333(87)90027-8

Breschi, S., \& Catalini, C. (2010). Tracing the links between science and technology: An exploratory analysis of scientists' and inventors' networks. Research Policy, 39(1), 14-26. doi:10.1016/j.respol.2009.11.004

Chang, S. B., Lai, K. K., \& Chang, S. M. (2009). Exploring technology diffusion and classification of business methods: Using the patent citation network. Technological Forecasting and Social Change, 76(1), $107-117$. doi:10.1016/j.techfore.2008.03.014

Chen, C., \& Hicks, D. (2004). Tracing knowledge diffusion. Scientometrics, 59(2), 199-211. doi:10.1023/ B:SCIE.0000018528.59913.48

Chen Y., Wang C., Ping Z., \& Liang T. (2011). National science library frontier program for young talents 47. Academic Press.

Choe, H., Lee, D. H., Kim, H. D., \& Seo, I. W. (2016). Structural properties and inter-organizational knowledge flows of patent citation network: The case of organic solar cells. Renewable \& Sustainable Energy Reviews, 55, 361-370. doi:10.1016/j.rser.2015.10.150

Choe, H., Lee, D. H., Seo, I. W., \& Kim, H. D. (2013). Patent citation network analysis for the domain of organic photovoltaic cells: Country, institution, and technology field. Renewable \& Sustainable Energy Reviews, 26, 492-505. doi:10.1016/j.rser.2013.05.037

Dighriri, M., Saeed Dayem Alfoudi, A., Myoung Lee, G., Baker, T., \& Pereira, R. (2018). Resource Allocation Scheme in 5G Network Slices. In 201832 nd International Conference on Advanced Information Networking and Applications Workshops (WAINA). Presented at the 2018 32nd International Conference on Advanced Information Networking and Applications Workshops (WAINA). IEEE. doi:10.1109/WAINA.2018.00098

Du, Y., Zhu, H., Yang, H., Wang, Z., \& Xu, Y. (2018). Overview of 5G mobile communication technology standards. Telecom Sci., 2.

Duncan, J. (1998). Collective Dynamics of Small World Networks. Nature, 393(6684), 440-442. doi:10.1038/30918 PMID:9623998

Geuna, A., \& Nesta, L. J. (2006). University patenting and its effects on academic research: The emerging European evidence. Research Policy, 35(6), 790-807. doi:10.1016/j.respol.2006.04.005

Griliches, Z. (1990). Patent Statistics as Economic Indicators: A Survey (No. w3301). National Bureau of Economic Research., doi:10.3386/w3301

Gupta, A., \& Jha, R. K. (2015). A Survey of 5G Network: Architecture and Emerging Technologies. IEEE Access: Practical Innovations, Open Solutions, 3, 1206-1232. doi:10.1109/ACCESS.2015.2461602

Han, D., Xu, F., \& Lang, B. (2018). Detailed explanation of global 5G standardization progress. Communications World, 45-47.

Han, Y. J., \& Park, Y. (2006). Patent network analysis of inter-industrial knowledge flows: The case of Korea between traditional and emerging industries. World Patent Information, 28(3), 235-247. doi:10.1016/j. wpi.2006.01.015

Han, Y. J., \& Park, Y. (2010). Patent network analysis of inter-industrial knowledge flows: The case of Korea between traditional and emerging industries. World Patent Information, 28(3), 235-247. doi:10.1016/j. wpi.2006.01.015 
Hu, F. (Ed.). (2016). Opportunities in 5 G Networks: A Research and Development Perspective. CRC Press. doi:10.1201/b19698

Hu, T. (2019). Get to know the five giants of 5G. Intellectual Property Management, 8, 7-14.

Hung, S. W., \& Wang, A. P. (2010). Examining the small world phenomenon in the patent citation network: A case study of the radio frequency identification (RFID) network. Scientometrics, 82(1), 121-134. doi:10.1007/ s11192-009-0032-z

IPlytics. (2019). Who is leading the 5G patent race? IPlytics Platf., 16.

ITU. (2018). Meeting the arrival of 5G: opportunities and challenges. Academic Press.

Jaffe, A. B., \& Trajtenberg, M. (1999). International knowledge flows: Evidence from patent citations. Economics of Innovation and New Technology, 8(1-2), 105-136. doi:10.1080/10438599900000006

Karki, M. (1997). Patent citation analysis: A policy analysis tool. World Patent Information, 19(4), 269-272. doi:10.1016/S0172-2190(97)00033-1

Kuusi, O., \& Meyer, M. (2007). Anticipating technological breakthroughs: Using bibliographic coupling to explore the nanotubes paradigm. Scientometrics, 70(3), 759-777. doi:10.1007/s11192-007-0311-5

Lee, C., Kwon, O., Kim, M., \& Kwon, D. (2018). Early identification of emerging technologies: A machine learning approach using multiple patent indicators. Technological Forecasting and Social Change, 127, 291-303. doi:10.1016/j.techfore.2017.10.002

Lee, S., \& Kim, M. (2010). Inter-technology networks to support innovation strategy: An analysis of Korea's new growth engines. Innovation (North Sydney, N.S.W.), 12(1), 88-104. doi:10.5172/impp.12.1.88

Li, Q. C., Niu, H., Papathanassiou, A. T., \& Wu, G. (2014). 5G Network Capacity: Key Elements and Technologies. IEEE Vehicular Technology Magazine, 9(1), 71-78. doi:10.1109/MVT.2013.2295070

Li, X., Chen, H., Huang, Z., \& Roco, M. C. (2007). Patent citation network in nanotechnology (1976-2004). Journal of Nanoparticle Research, 9(3), 337-352. doi:10.1007/s11051-006-9194-2

Liu, G. (2014). Research on the establishment of domestic patent intelligence analysis method system. Intell. Mag., 16-21.

Liu, W., Dong, J., \& Ren, Y. (2018). Research and verification of key problems of commercial 5G network. Telecom Sci., 7.

Liu, Y., \& Li, Y. (n.d.). Fifth generation mobile communication technology patent information analysis and strategy. Science and Technology Management Research, 36(355), 162-167.

Lu, M. (2018). Which is the most conscientious to publish the standard of $5 G$ patent fee? https://baijiahao.baidu. $\mathrm{com} / \mathrm{s}$ ?id=1609951024422659511\&wfr $=$ spider $\&$ for $=\mathrm{pc}$

Luan, C., \& Zeng, G. (2011). Research on measure of core technology field based on SNA. Libr. Inf. Work, $55,33-52$.

Lv, Y., \& Kang, Y. (2010). Research and application of patent layout based on visualization. Journal of Intelligence, 29, 300-304.

Madani, F., \& Weber, C. (2016). The evolution of patent mining: Applying bibliometrics analysis and keyword network analysis. World Patent Information, 46, 32-48. doi:10.1016/j.wpi.2016.05.008

No, H. J., \& Park, Y. (2010). Trajectory patterns of technology fusion: Trend analysis and taxonomical grouping in nanobiotechnology. Technological Forecasting and Social Change, 77(1), 63-75. doi:10.1016/j. techfore.2009.06.006

Sharma, P. (2013). Evolution of Mobile Wireless Communication Networks-1G to $5 G$ as well as Future Prospective of Next Generation Communication Network 7. Academic Press.

Sternitzke, C., Bartkowski, A., \& Schramm, R. (2008). Visualizing patent statistics by means of social network analysis tools. World Patent Information, 30(2), 115-131. doi:10.1016/j.wpi.2007.08.003 
Stolpe, M. (2002). Determinants of knowledge diffusion as evidenced in patent data: The case of liquid crystal display technology. Research Policy, 31(7), 1181-1198. doi:10.1016/S0048-7333(01)00192-5

Wang, X., Liu, Z., \& Hou, H. (2010). Analysis of enterprise technology development and technology competition based on patent co-citation: A case study of industrial enterprises in the world top 500. Sci. Res. Manag., 31, $127-138$.

Wilhelmsson, M. (2009). The spatial distribution of inventor networks. The Annals of Regional Science, 43(3), 645-668. doi:10.1007/s00168-008-0257-4

WIPO. (2018). World intellectual property indicators 2018. World Intellectual Property Organization.

Xiang, X., \& Cai, H. (2012). Application of social network analysis based on patent citation in knowledge management research. Journal of Management, 9, 562.

Xiao, X., \& Zhao, H. (2017). Analysis of competitive situation of $5 \mathrm{~g}$ communication enterprises based on patent measurement. Telecom Engineering Technics and Standardization, 47.

Yang, B., \& Zhang, X. (2008). Application of patent network analysis in technology roadmap. Data Anal. Knowl. Discov., 24, 61-66.

Zhang, G., Guan, J., \& Liu, X. (2014). The impact of small world on patent productivity in china. Scientometrics, 98(2), 945-960. doi:10.1007/s11192-013-1142-1

Zhang, H., Liu, N., Chu, X., Long, K., Aghvami, A., \& Leung, V. C. M. (2017). Network Slicing Based $5 G$ and Future Mobile Networks: Mobility, Resource Management, and Challenges. arXiv:1704.07038 [cs, math].

Zhang, J., Cui, J., Zhai, D., \& Xiao, Y. (2011). Research on the application of SNA in patent analysis. Sci. Technol. Manag. Res., 31, 168-171.

Zhang, R., \& Xiao, G. (2013). Enterprise patent intelligence analysis based on social network analysis. Intell. Mag., 32, 34-39.

Zhang, Y. (2019). 5G will fully enable the industrial Internet. Telecom Sci., 1-8.

Hui (Eva) Zhang o with MSc in Business Analytics with Distinction from the University of Liverpool, UK and Xi'an Jiaotong-Liverpool University, China. She was Prof Chang's student between Sep 2018 and January 2019. She worked as a part-time research assistant with Prof. Chang until May 2019. This paper was led by her as part of her MSc research project supervised by Dr. Dr. Kok Hoe Wong.

Kok Hoe Wong $(P h D)$ has worked for several renowned Multi-National Corporations (MNCs) before embarking into academia the last 10 years. His forte is in software engineering, project management, teaching and academic management. He has extensive experiences in architecting and managing enterprise-level IT projects, working with stakeholders from different parts of the world. Upon his arrival in China in 2007, he has progressed from being a Senior Lecturer to Vice President at a local institution, overseeing a successful Sino-Foreign partnership with Staffordshire University, UK. In recognition of his contributions, he had received several awards from the SuZhou government that include the "SIP Education Talent Award". He is currently the Deputy Head of Computer Science and Software Engineering department at Xi'an Jiaotong-Liverpool University.

Victor Chang (Prof.) is a Professor of Data Science and IS at Teesside University, UK. He was a Senior Associate Professor, Xi'an Jiaotong-Liverpool University between June 2016 and Aug 2019. He was a Senior Lecturer at Leeds Beckett University, UK between Sep 2012 and May 2016. Within 4 years, he completed Ph.D. (CS, Southampton) and PGCert (HE, Fellow, Greenwich) while working for several projects. Before becoming an academic, he achieved $97 \%$ on average in 27 IT certifications. He won an IEEE Outstanding Service Award in 2015, best papers in 2012, 2015 \& 2018, 2016 European award: Best Project in Research, 2017 Outstanding Young Scientist and numerous awards since 2012. He is widely regarded as a leading expert on Big Data/Cloud/loT/security. He is a visiting scholar/PhD examiner at several universities, an Editor-in-Chief of IJOCI \& OJBD, former Editor of FGCS, Associate Editor of TII \& Info Fusion, founding chair of international workshops and founding Conference Chair of IOTBDS, COMPLEXIS, FEMIB \& IIOTBDSC. He was involved in projects worth more than £13 million in Europe and Asia. He published 3 books and edited 2 books. He gave 18 keynotes internationally as a top researcher. 